\title{
Characterization of Flow Induced Anisotropy in Sheet Metal at Large Strain
}

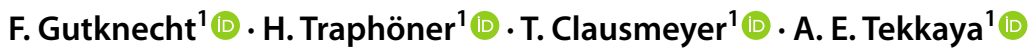

Received: 21 January 2021 / Accepted: 4 September 2021 / Published online: 29 October 2021

(c) The Author(s) 2021

\begin{abstract}
Background Many metals exhibit a stress overshoot, the so-called cross-hardening when subjected to a specific strain-path change. Existing tests for sheet metals are limited to an equivalent prestrain of 0.2 and show varying levels of cross-hardening for identical grades.

Objective The aim is to determine cross-hardening at large strains, relevant for forming processes. Mild steel grades (DC04, DC06, DX56) and high strength steel grades (BS600, DP600, ZE800) are investigated to quantify the level of cross-hardening between different grades and reveal which grades exhibit cross-hardening at all.

Method A novel test setup for large prestrain using hydraulic bulge test and torsion of curved sheets is developed to achieve an orthogonal strain-path change, i.e. the strain rate tensors for two subsequent loadings are orthogonal. The influence of strain rate differences between the tests and clamping of curved sheets on the determined cross-hardening are evaluated. The results are compared to experiments in literature.

Results Cross-hardening for sheet metal at prestrains up to 0.6 true plastic strain are obtained for the first time. For DX56 grade the maximum cross-hardening for all prestrains have a constant level of approximately $6 \%$, while the maximum cross-hardening for DC04 and DC06 grades increases, with levels between 7 and 11\%. The high strength grades BS600 and ZE800 do not show cross-hardening behavior, while, differencing from previous publications, cross-hardening is observed for dual phase steel DP600.

Conclusion Depending on the microstructure of the steel grade the cross-hardening increases with large prestrain or remains constant.
\end{abstract}

Keywords Experimental characterization $\cdot$ Sheet metal - Cross-hardening $\cdot$ Mechanical behavior

\section{Introduction}

Manufacturing of metal components often involves changing stress and strain states in the material during the forming process (e.g., shear and plane strain tension at deep-drawing). Changes in the stress states lead to non-linear strain-paths in the material and their effects need to be considered in manufacturing. The non-linear strain-path not only affects the failure of the material [1], but also affects its yield strength. Depending on the type of strain-path change, the yield stress might decrease (load reversal) or increase (orthogonal

F. Gutknecht

Florian.Gutknecht@iul.tu-dortmund.de

1 Institute of Forming Technology and Lightweight Components (IUL), TU Dortmund University, Baroper Str. 303, 44227 Dortmund, Germany strain-path change) [2]. The effect of reduced yield stress after load reversal is known as Bauschinger effect and an increased yield stress after orthogonal strain-path change is often referred to as cross-hardening.

Different theories for the explanation of cross-hardening on the microstructural level exist. A widely accepted explanation is based on the fact that a given monotonic strain-path causes a characteristic pattern of dislocation accumulations, called dense dislocation walls [3]. An orthogonal strain-path change then activates new glide systems. The dense dislocation walls from previous monotonic loading are then a barrier which results in a stress overshoot on the macroscopic scale [2]. This is referred to as cross-hardening. With further loading the previous dislocation accumulations are dissolved and a new pattern of dislocation accumulation, specific for the new loading path, establishes. The cross-hardening effect has been observed for sheet metals with body-centered cubic 
(bcc) crystal lattice [4] and face-centered cubic (fcc) crystal lattice [5]. However, not all metals with such lattice show cross-hardening. For example, dual-phase steels with their ferritic and martensite phases, both bcc, have been reported to show no cross-hardening at all [6]. Based on these reports one could conclude, that an ideal condition for cross-hardening is the initially unhindered mobility of dislocations within the grain. This means, a) that within a grain, which experienced deformation, a change of the active glide systems is to occur with subsequent deformation and, b) that dislocation glide within a grain is not hindered by imperfections like carbides or grain boundaries. The latter could be achieved if the microstructure:

- is single-phase

- has large average grain size

- small amount of carbon or other alloying elements, which might lead to additional phases or precipitates

Yet, other works have questioned the importance of dense dislocation walls on cross-hardening effect and claim a greater importance of texture evolution [7].

The cross-hardening may be interpreted as a special form of anisotropic hardening, which leads to a modification of the yield stress. The first model of that kind was introduced by Teodosiu and $\mathrm{Hu}$ [8]. Later different variants have been presented by Choi et al. [9] and Mánik et al. [10]. Another admissible interpretation postulates instead a distortion of the yield surface, due to the evolution of a Hill-type anisotropy tensor. Exemplary models have been introduced by Levkovitch and Svendsen [11] and Feigenbaum and Dafalias [12]. Recently, Barlat et al. [13] proposed a modification of the homogenous anisotropic hardening model (HAH) to capture cross-hardening effects. In subsequent work a more general modification was suggested to enhance the HAH model [14].

The occurrence of cross-hardening is characterized by a stress overshoot $\Delta \sigma$ Fig. 1(a), which is typically maximum directly after the strain-path change [10]. A transient region follows afterwards, where the work hardening is either reduced, stagnating or even negative (i.e., softening occurs). Figure 1(b) illustrates the different behavior for a sequence of simple shear experiments in different orientations with respect to the initial loading direction for mild steel [2].

It is sometimes observed for continued strain after the orthogonal strain-path change that the flow curve after strain-path changes becomes parallel to or coincides with the monotonic curve [15]. The amount of the stress overshoot and the length of the transient zone depend on the amount of prestrain [2].

While the choice of material is critical, whether crosshardening may occur at all, the realization of the orthogonal strain-path change has significant influence as well. The

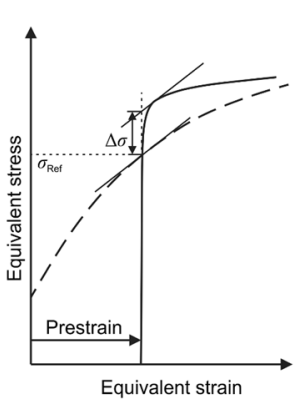

(a)

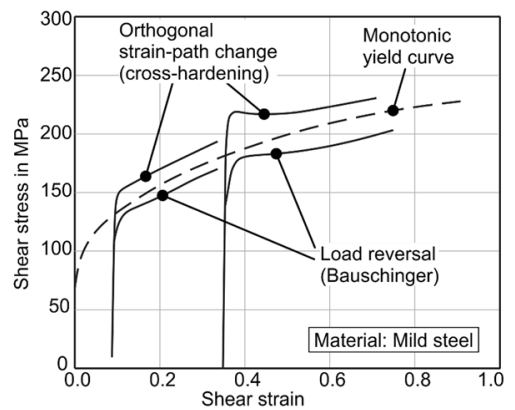

(b)
Fig. 1 (a) Definition of stress overshoot $\Delta \sigma$ [10]. (b) Exemplary stress overshoot for a mild steel [2]

magnitude of cross-hardening is maximum, when the strainpath change is abrupt (i.e. no gradual changes in the strainpath) [16] and when the subsequent strain states are perfectly orthogonal [2]. Schmitt et al. [17] proposed to measure the strain-path change of two subsequent and discrete load steps by

$\kappa=\frac{\Delta \varepsilon_{1}^{\mathrm{pl}}: \Delta \varepsilon_{2}^{\mathrm{pl}}}{\left\|\Delta \varepsilon_{1}^{\mathrm{pl}}\right\|\left\|\Delta \varepsilon_{2}^{\mathrm{pl}}\right\|}$.

Here, $\Delta \varepsilon_{i}^{\mathrm{pl}}$ is the tensor corresponding to the plastic strain increment of load step $i$. Thus, $\kappa=1$ represents the monotonic case (i.e., linear strain-path). Values of 0 and -1 represent orthogonal strain-path change and a reversed strain-path, respectively.

For the experimental characterization of the cross-hardening in sheet metals, various two-step setups have been investigated to achieve an orthogonal strain-path change (Table 1). In general, one of the first observations of cross-hardening has been reported for a sequence of biaxial tension and uniaxial tension [18]. For the investigated steel the biaxial prestrain was below 0.2 . Later setups mostly used uniaxial tensile or plane strain tensile tests. The prestrain in such approaches is limited to approximately 0.2 or less, as the strain field must be homogeneous to ensure the uniformity of the deformation in the second stage. Shear tests allow much higher uniform strains, but at high strains the shear deformation causes significant change of texture anisotropy. To minimize the influence of changing texture Bouvier et al. [24] recommend to limit the shear strain to 0.4 , which roughly corresponds to an equivalent strain of 0.2 . A common approach is to test a large specimen in the first step and mechanically separate miniaturized specimens under various angles for the second step. The existing tests have some disadvantages, which are namely:

- trimming operations (e.g., machining, cutting) in the examination surface for subsequent specimens 
Table 1 Selected setups for orthogonal strain-path change in sheet metals

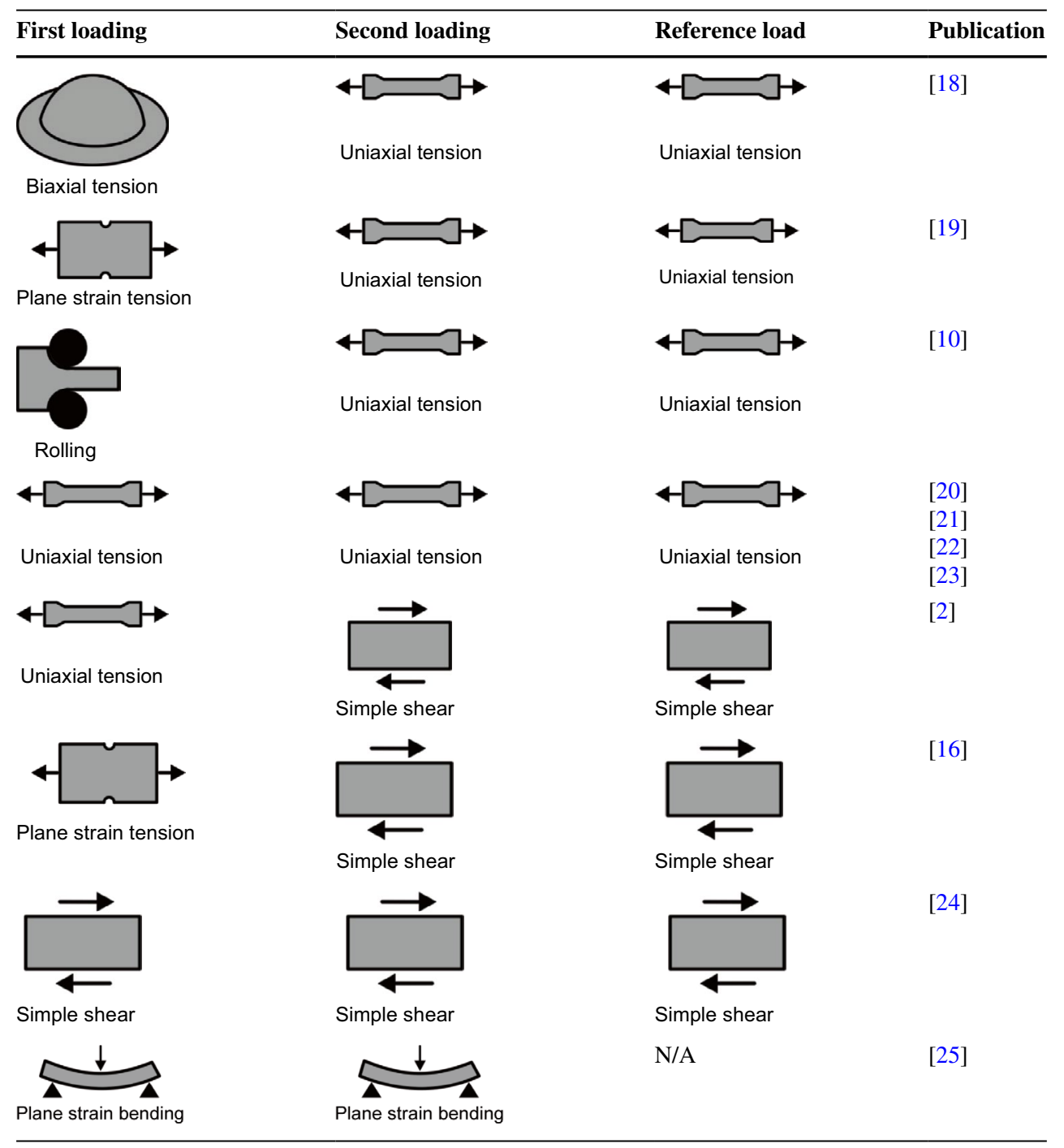

- limited to (equivalent) prestrain of approximately 0.2 when using shear, plane-strain or uniaxial tension in the first step

Material removal between subsequent tests might release residual stresses (both on the micro scale and the macro scale), or even change the material at the edge (e.g. laser-cutting). As these influences on cross-hardening are not quantified yet, it is advisable to avoid material removal. Larger strains are of interest for forming technologies, where significantly larger strains occur. Typically strains are as large as 1.0 true plastic strain in sheet metal forming and even 2.5 true plastic strain in sheet-bulk metal forming [26].

In general, two classes of tests can be distinguished. Setups combining different types of loading e.g., tension and shear (cf. Fig. 2(a)), require a suitable measure to compare the different type of strains. A frequent choice for the equivalent strain is the use of the isotropic von Mises model [27], or the simplified Hill model with a single $r_{n}$ value, assuming transversal isotropy [28]. Another physically motivated solution is to compare the dissipated plastic work [29]. The other class of tests are setups maintaining the loading type e.g., 


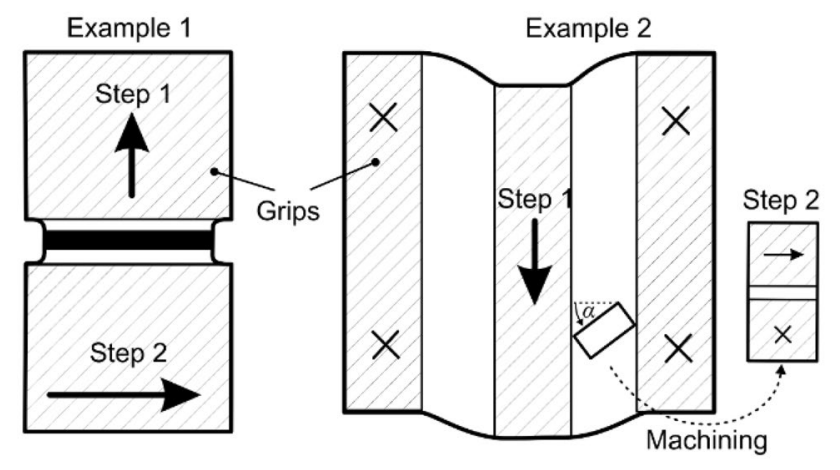

(a)

(b)

Fig. 2 Tests for orthogonal strain-path changes. (a) Sequence of plane-strain tension and simple shear, [16]. (b) Sequence of simple shear in $0^{\circ}$ and $45^{\circ}$ rolling direction, [24]

shear followed by shear, but changing the angle of loading (Fig. 2(b)). The necessary angle for an orthogonal strainpath change between tensile tests depends on the anisotropy [24]. As the sheet's anisotropy varies with the orientation in the sheet plane and with the amount of plastic strain, a perfect orthogonal strain-path change, i.e. $\kappa=0$, is cumbersome to obtain with this approach. In this regard it is noteworthy that the orthogonality of subsequent strains and not necessarily the orthogonality of the outer loads is relevant. E.g., loading of an isotropic sheet in uniaxial tension in rolling direction and subsequently in transverse direction would result in $\kappa=-0.5$.

Besides the setup for the orthogonal strain-path change an additional monotonic test, the reference test, is required to determine any macroscopic cross-hardening effect. The reference test needs to enable large monotonic strain, such that the sum of prestrain and subsequent loading are covered.

This short review of existing tests and the demand of forming applications help to postulate requirements for an ideal characterization test for cross-hardening:

1. The change of strain path should be abrupt.

2. The change of strain path should be purely orthogonal.
3. The orthogonality should be accomplished independently of a material's anisotropy.

4. Uniform strain distribution after the first test sequence is required.

5. The first load step should enable large strains.

6. A suitable measure to compare the subsequent testing stages is used.

7. Mechanical manipulation of the material should be avoided.

To the best knowledge of the authors there exists no test in the literature, which fulfills all the above listed requirements. This is especially the case for the large prestrains. But even for smaller prestrains there are only a few tests left, which can ensure purely orthogonal strain-path changes or do not require mechanical manipulation. The proposed setup aims to provide a test, which fulfills all the above requirements. The test is used to compare different steel grades directly to check the hypothesis on ideal conditions in the microstructure for occurrence of cross-hardening and explicitly quantify the amount of cross-hardening.

In the next section details of the investigated steel grades and the used conventional tests are introduced. Subsequently, the design of the new test setup with analyses justifying that the ideal conditions aimed at are met is presented. Afterwards the stress over-shoot and cross-hardening are presented and discussed.

\section{Materials and Basic Test Setups}

Initially the investigated materials and their most relevant characteristics are presented. This is followed by a brief presentation of used conventional experiments, the hydraulic bulge test and the in-plane torsion test.

\section{Materials Tested}

To clarify which materials are likely to show cross-hardening, different steel grades from different suppliers have been selected.
Table 2 Microstructural information and estimation of cross-hardening tendency

\begin{tabular}{lllllll}
\hline Type & Material number & $\begin{array}{l}\text { Specification } \\
\text { (VDA } \\
\text { 239-100) }\end{array}$ & $\begin{array}{l}\text { Nominal } \\
\text { thickness } t \text { in } \\
\text { mm }\end{array}$ & $\begin{array}{l}\text { Average } \\
\text { Grain size } \\
\text { in } \mu \mathrm{m}\end{array}$ & $\begin{array}{l}\text { Carbon in } \\
\text { weight- } \%\end{array}$ & $\begin{array}{l}\text { Expected } \\
\text { cross- } \\
\text { hardening }\end{array}$ \\
\hline DC06 & 1.0873 & CR5 & 1.0 & 9.5 & 0.02 & + \\
DC04 & 1.0338 & CR3 & 2.0 & 27.5 & 0.06 & + \\
DX56 & 1.0963 & CR4 & 1.0 & 15.0 & 0.16 & + \\
BS600 & 1.0988 & HR500Y & 2.0 & 27.0 & 0.11 & $?$ \\
DP600 & - & CR330Y590T-DP & 2.0 & 8.5 & 0.12 & 0 \\
ZE800 & 1.0556 & CR800LA & 1.6 & 35.0 & 0.10 & $?$ \\
& & +annealed & & & & $?$ \\
\hline
\end{tabular}


The carbon content and the average grain size are determined as shown in Table 2. For better comparability the material specification according to VDA 239-100 [30] is provided. The mechanical properties have been determined by tensile tests (Table 3). The determination of the initial yield stress $R_{\mathrm{p} 0.2}$ and the ultimate strength $R_{\mathrm{m}}$ are defined in EN-ISO standard 6892 [31]. The strain hardening exponent $n$ is defined in EN-ISO standard 10275 [32] and describes the increase of true stress $\sigma$ with the increase of true plastic strain $\varepsilon$ between the initial yield stress $R_{\mathrm{p} 0.2}$ and the end of uniform strain in the uniaxial tensile test by the equation $\sigma=C \cdot \varepsilon^{n}$, where $C$ is the so-called strength coefficient. The parameter $r_{i}$ relates the amount of strain in width and thickness direction in uniaxial tensile test with angle $i$ with respect to the rolling direction. The normal anisotropy $r_{\mathrm{n}}=\frac{r_{0}+2 r_{45}+r_{90}}{4}$ yields the average anisotropy, according to EN-ISO 10113 [33]. DC06, DC04 and DX56 are mild steels with an interstitial-free (IF) microstructure. All three grades are cold rolled and exhibit significant hardening $(n \approx 0.25)$ as well as normal anisotropy $\left(r_{\mathrm{n}} \approx 2\right)$. They differ by the amount of carbon and their average grain sizes. DX56 has 0.16 weight percent carbon, which is the most among all investigated grades, while DC06 has the lowest amount of carbon content $(0.02 \%)$. Cross-hardening has been reported for the latter by $[6,24,34]$ (Fig. 13). The mechanical behavior of DC04 and DX56 have not been tested for orthogonal strain-path changes previously. Due to the same metallurgical concept as DC06 they are expected to exhibit cross-hardening. The larger grain sizes might cause a more severe stress overshoot especially for large prestrain, as larger grains allow the dislocations to form more pronounced dense dislocation walls. Yet, the increased carbon content might cause more intragranular imperfections which obstruct mobility of dislocations. Therefore, the magnitude of cross-hardening (compared to DC06) is of special interest.

In the class of modern high strength steels different candidates are considered. BS600 is a virtually single-phase bainitic steel, according to the supplier. It has a large grain size and moderate carbon content compared to mild steels. Differing from the other mild and high strength grades, the steel is hot rolled. Its potential for cross-hardening is unknown, but some cross-hardening might be expected, due to its large single-phase grains and moderate carbon content.
DP600 is an example of a dual-phase steel with ferritic and martensite phases. Deformation occurs mostly in the ferritic phase. Due to the dual-phase concept the average ferritic grain size is quite small $(9 \mu \mathrm{m})$. Principally, a crosshardening effect might be possible. Yet, no cross-hardening effect has been reported in literature, up to equivalent strain levels of 0.2. The novel setup enables characterization for larger prestrain. ZE800 is a micro-alloyed grade which has been recovery annealed. The moderate content of carbon $(0.1 \%)$ and the largest grain-size of all investigated grades should enable occurrence of cross-hardening. Yet, its potential for cross-hardening is unknow so far. Microsections of the investigated grades are presented in Appendix A.

\section{Prestrain Test: Hydraulic Bulge Test}

The hydraulic bulge test is performed on a Zwick BUP1000 hydraulic testing machine. The strain field is measured optically during the test with a GOM Aramis $4 \mathrm{M}$ digital imaging correlation (DIC) system. The DIC system uses discrete local fields, so-called facets which incorporate a finite number of pixels (here: $19 \times 19$ pixels) and a defined regular distance to each other (here: 16 pixels). Together with the resolution of the camera (here: $2358 \times 1728$ pixels) and the size of the measuring area (here: $155 \mathrm{~mm} \times 115 \mathrm{~mm}$ ) an equivalent strain gauge length can be determined which is approximately two times the distance of the facets [35]. The equivalent strain gauge length is $2 \mathrm{~mm}$ for the bulge test. The inner die diameter is $D_{\text {Die }}=120 \mathrm{~mm}$. The velocity of the punch, which pushes the hydraulic oil into the test chamber is set $0.1 \mathrm{~mm} / \mathrm{s}$ to ensure quasi-static loading of the sheet. The equivalent strain rate varies during the process, but remains below $0.011 / \mathrm{s}$ (Fig. 10). At the pole meridional stress $\sigma_{\theta}$ and circumferential stress $\sigma_{\varphi}$ are identical and referred to as biaxial stress $\sigma_{\mathrm{B}}$. The thickness strain $\varepsilon_{\mathrm{p}}$ and biaxial Cauchy stress $\sigma_{\mathrm{B}}$ are determined according to the EN-ISO 16808 standard [36]. Both, stress and strain are required to compute the specific work
Table 3 Mechanical properties from tensile tests

\begin{tabular}{llllll}
\hline Type & $\begin{array}{l}\text { Yield stress } R_{\mathrm{p} 0.2} \\
\text { in MPa }\end{array}$ & $\begin{array}{l}\text { Ultimate strength } \\
R_{\mathrm{m}} \text { in MPa }\end{array}$ & Uniform strain & $\begin{array}{l}\text { Hardening } \\
\text { exponent } n\end{array}$ & $\begin{array}{l}\text { Normal } \\
\text { anisotropy } \\
r_{\mathrm{n}}\end{array}$ \\
\hline DC06 & 149 & 238 & 0.27 & 0.268 & 2.00 \\
DC04 & 177 & 304 & 0.23 & 0.233 & 1.91 \\
DX56 & 161 & 293 & 0.25 & 0.252 & 2.19 \\
BS600 & 535 & 605 & 0.06 & 0.060 & 0.80 \\
DP600 & 369 & 597 & 0.16 & 0.179 & 1.02 \\
ZE800 & 809 & 834 & 0.05 & 0.040 & 1.20 \\
\hline
\end{tabular}




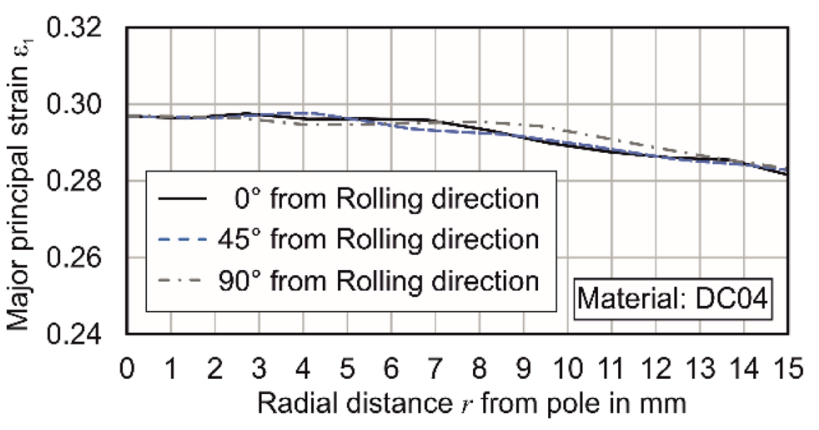

Fig. 3 Major principal strains in meridional direction after bulge test for DC04

$w=\int_{0}^{t_{\text {Experiment }}} \boldsymbol{\sigma}: \boldsymbol{D} d t=\int_{0}^{\mathcal{E}_{\mathrm{p}}} \sigma_{\mathrm{B}} d \varepsilon$

where $\boldsymbol{D}$ is the plastic rate of deformation tensor. The measured curvature radius $R$ of the sheet and calculated work for all tests are given in Appendix B.

One requirement for an ideal characterization test to determine cross-hardening, is that the deformation in the gauge area after the first test is homogeneous. In fact, the gradient of strain in meridional direction (Fig. 3) does not influence the evaluation of the shear stress, which is always calculated for a specific radius. Thus, for the concept of bulge-torsion the requirement reduces to homogeneity of the strain in circumferential direction.

The subsequent torsion after the bulge test is evaluated at $r=10.5 \mathrm{~mm}$. At this radius the major principal strain is $\varepsilon_{1}=0.2895 \pm 0.0019$ for DC04, which is considered as sufficiently homogenous.

\section{In-Plane Torsion Test for Plane and Curved Sheets}

The setup for testing of plane sheets is given in [38] and illustrated in (Fig. 4(a)). For testing of bulged specimen an analogous setup is used (Fig. 5). The clamping radii for the

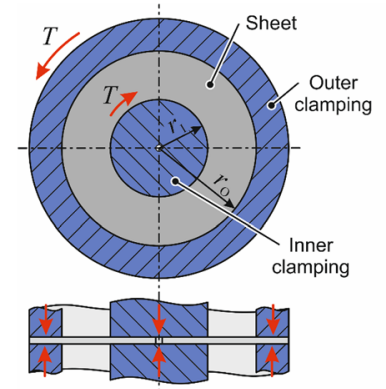

(a)

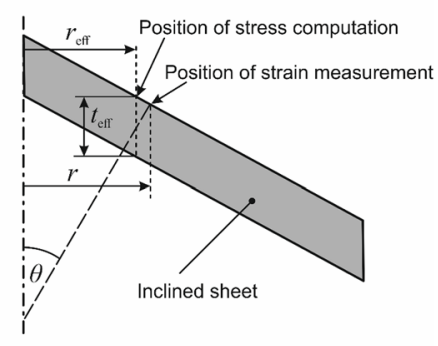

(b)
Fig. 4 (a) Principle of the in-plane torsion test [37]. (b) Stress computation for inclined sheets bulged specimen are $r_{\mathrm{I}}=10 \mathrm{~mm}$ and $r_{\mathrm{O}}=91 \mathrm{~mm}$ for the inner clamping and outer clamping, respectively.

In the current experiments the shear strain $\gamma_{\text {Torsion }}$ is measured using the Aramis 5M DIC system from GOM, with an equivalent strain gauge length of $0.2 \mathrm{~mm}$. Details of the equipment and the post-processing parameters are presented in [35]. Typical strain fields are presented in Appendix D. For inclined sheets the shear stress at the torsion test is constant in the normal of the sheet direction [39]. Therefore, the radius of the point where the strain is measured and the radius of the corresponding cross-section for stress evaluation are no longer identical in the torsion test (Fig. 4(b)). The shear stress $\tau_{\varphi r}$ depends on the effective radius $r_{\text {eff }}$

$\tau_{\varphi r}=\frac{T}{2 \cdot \pi \cdot r_{\mathrm{eff}}^{2} \cdot t_{\mathrm{eff}}}$,

where $T$ is the measured torque on the inner clamping, while the effective radius and the sheet thickness in vertical direction are given as:

$r_{\text {eff }}=r-\frac{1}{2} \cdot t \cdot \sin (\theta) t_{\text {eff }}=\frac{t}{\cos (\theta)}$

In both equations the sheet thickness $t$ after the bulge test is calculated from the measured sheet thickness before the bulge test and the obtained strain by DIC in the bulge test. For the largest evaluation radius $r=10.5 \mathrm{~mm}$ and the smallest curvature radius of the sheet $R=65 \mathrm{~mm}$ the corresponding angle $\theta=9.4^{\circ}$. The above equations have been validated for angles up to at least $35^{\circ}$.

$w=\int_{0}^{t_{\text {Experiment }}} \boldsymbol{\sigma}: \boldsymbol{D} d t=\int_{0}^{\gamma_{\text {Torsion }}} \tau_{\varphi r} d \gamma$

The torsion of the curved sheets is usually evaluated at $r=10.5 \mathrm{~mm}$, only for prestrains above 0.4 the evaluation radius is changed to $r=10.4 \mathrm{~mm}$. With increasing distance from the inner clamping, the detection quality of DIC pattern is improved. Yet, the amount of deformation decreases.

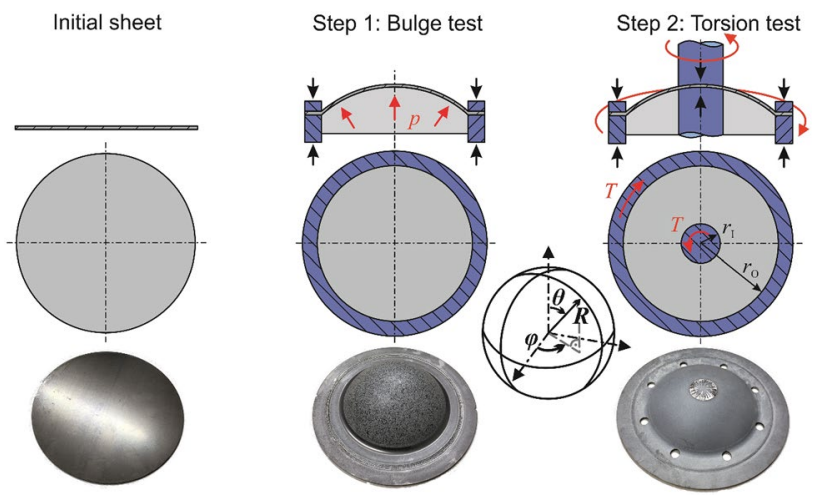

Fig. 5 Scheme of proposed bulge-torsion test 
Both distances have a sufficient quality for evaluation. The influence of different evaluation radii on the stress-strain curve is given in Appendix C. The uncertainty in the shear stress calculation is below $0.35 \%$ for all investigated cases [40]. From the Cauchy shear stress $\tau_{\varphi r}$ and the shear strain $\gamma_{\text {Torsion }}$ the specific work $w$ is determined.

\section{Design of New Test}

First, the concept of the new proposed bulge-torsion test (BTT) is introduced. Then, orthogonality of the strain sequence is analyzed and modifications for the in-plane torsion of curved sheets are presented. Afterwards the procedure for cross-hardening analysis is described. Finally, influences on the determination of stress and strain are investigated and the advantages and limitations of the test are discussed.

\section{Concept of the Bulge-Torsion Test}

The proposed experiment involves two steps (Fig. 5). In the first step a conventional bulge test is conducted until a given pole height is reached. In the second step the pre-bulged specimen is loaded with coaxial torsion with respect to the rotational axis of the specimen, analogous to the classic inplane torsion test in the previous section. The general idea was presented in [41] by the authors.

For the analysis of the proposed experiment, a spherical coordinate system with the unit vectors $\boldsymbol{e}_{r}, \boldsymbol{e}_{\theta}, \boldsymbol{e}_{\varphi}$ is used. Here, $r$ is the radial distance from the center. For an ideal sphere, the thickness direction of the sphere is parallel to $e_{r}$.

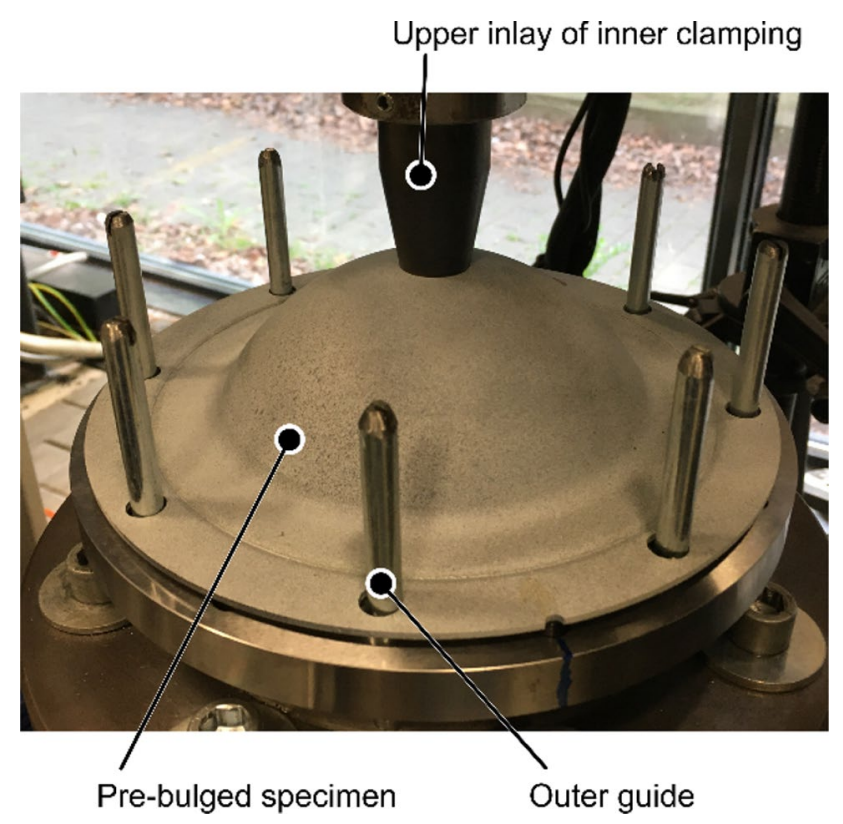

Fig. 6 Integration of curved specimen at the in-plane torsion test
During the hydraulic bulge test. Only $\sigma_{\theta}$ and $\sigma_{\varphi}$ differ from zero. According to the Levy-Mises flow rule the deviatoric Cauchy stress $\sigma_{i j}^{\prime}$ is directly proportional to the rate of plastic strain. Thus:

$D_{\theta \theta} \neq 0 ; D_{\varphi \varphi} \neq 0 ; D_{r r} \neq 0$

where $D_{i j}$ is the rate of deformation tensor. In the subsequent step, the semi-hemispherical sheet is loaded in torsion. For the given setup the shear strain is constant in normal direction to the surface [39]. Thus, the only non-zero stresses are $\tau_{\theta \varphi}=\tau_{\varphi \theta}$. The resulting directions of plastic strain rates are:

$D_{\theta \varphi}=D_{\varphi \theta} \neq 0$

Consequently, the scalar product of $D_{i j \text {,bulge }}$ with $D_{i j}$, torsion is zero, independent of the sheet's plastic anisotropy. Due to the proportional loading in the bulge test and the torsion test, also the strain increments $\Delta \varepsilon_{\text {bulge }}^{\mathrm{pl}}$ and $\Delta \varepsilon_{\text {torsion }}^{\mathrm{pl}}$ are parallel to $D_{i j \text {,bulge }}$ with $D_{i j \text {, torsion }}$, respectively. Hence, according to (equation (1)) it is expected to achieve ideal orthogonal loading $(\kappa=0)$.

The bulge test is performed as described in the previous section without any modification of the conventional setup. The subsequent torsion test is implemented in the setup of the classic in-plane torsion test for plane sheets, with the following modifications for the curved sheets. The outer clamps are replaced by guides (Fig. 6). The upper and lower inner clamps are replaced by sets of adjusted inlays for the upper and lower clamps to transmit the torque through the

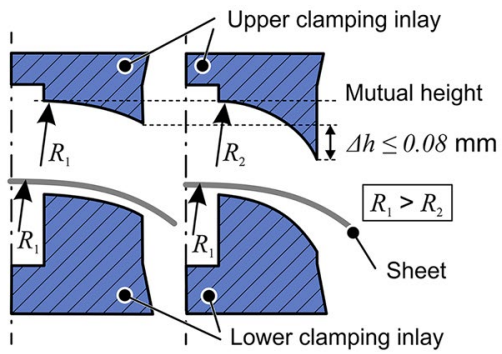

(a)

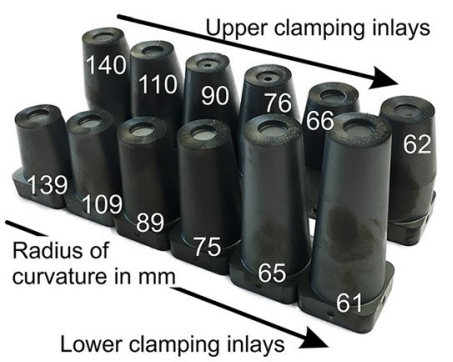

(b)

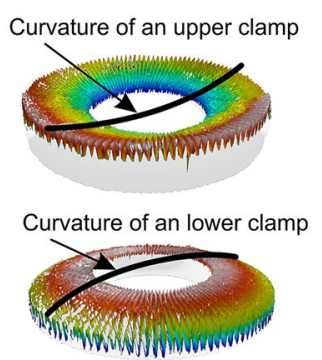

(c)
Fig. 7 (a) Concept of clamp design and definition of maximum height deviation between two curvatures. (b) Set of clamping inlays with respective curvature radius. (c) Exemplary topography of upper and lower clamp determined by confocal microscopy 
pre-bulged sheet (Fig. 7(a)). Ideally, the radius of the inner clamp matches exactly the radius of the bulged sheet.

However, this would require an infinite number of clamps. Therefore, a finite number of clamps with discrete levels of curvature are chosen, such that the vertical difference $\Delta h$ at the outermost point of the clamps surface to the next larger/smaller curvature radius is lower than $0.08 \mathrm{~mm}$. Consequently, six clamping sets have been designed. In order to compensate the sheet thickness, the lower clamps have been designed with $1 \mathrm{~mm}$ less curvature radius than the corresponding upper clamp (Fig. 7(b)). The curved clamp surfaces are designed with grooves to increase the transmissible torque (Fig. 7(c)).

The strains on the sheets are measured via DIC. After the bulge test and before the torsion test the sprayed DIC pattern is removed and re-applied. This is necessary due to the different measuring volumes.

\section{Analysis Procedure}

The determination of a cross-hardening effect requires the comparison of the stress after the orthogonal strain-path

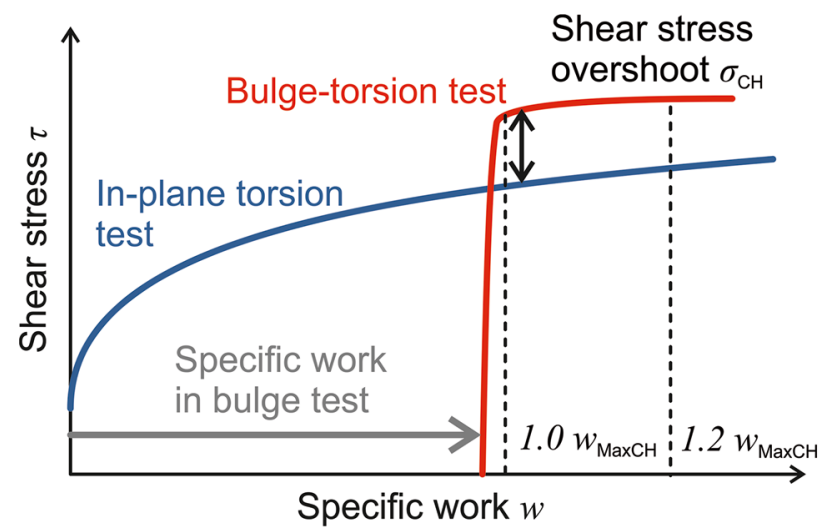

(a)

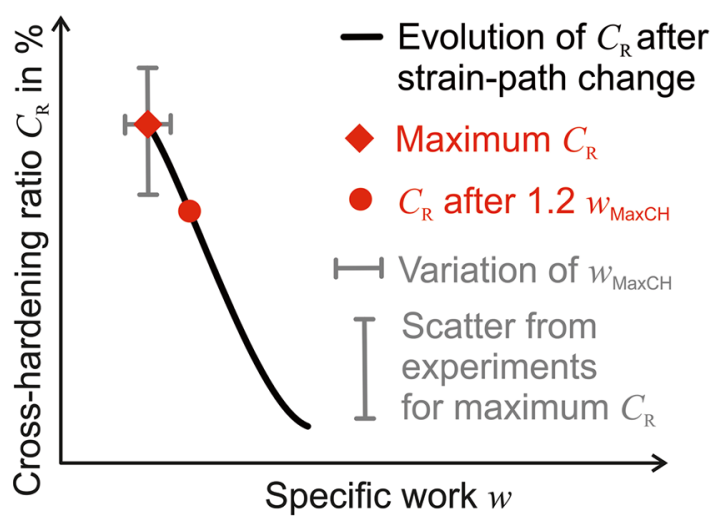

(b)

Fig. 8 Determination of orthogonal strain-path change effects. (a) Stress overshoot, (b) cross-hardening $(\mathrm{CH})$ change with a monotonic reference stress. Both, the bulgetorsion test (after bulge test) and the in-plane torsion test (monotonic torsion) are simple shear tests. Therefore, the absolute shear stress of both can be directly compared. For the shear strain this is not permissible, as the biaxial tension has caused some (intended) prestrain. Both loads can be compared by the specific work $w$ (equation (2) and (5)) Thus, the shear-stress of the bulge-torsion test is shifted by the specific work applied during the hydraulic bulge test and can then be compared to the monotonic shear test (Fig. 8(a)). Differing from the previous definition of $\Delta \sigma$ (cf. Fig. 1(a)) the positive difference between the shear stress of bulgetorsion test and in-plane torsion test at the same specific work $w^{*}$ defines the amount of shear stress overshoot

$\sigma_{\mathrm{CH}}\left(w^{*}\right)=\sigma_{\text {bulge-torsion }}\left(w^{*}\right)-\sigma_{\text {in-plane torsion }}\left(w^{*}\right)$.

In general, the hardening rate after an orthogonal strainpath change is reduced, compared to the monotonic hardening rate. Therefore, $\sigma_{\mathrm{CH}}$ tends to decrease with further deformation. The stress overshoot for a given specific work $\sigma_{\mathrm{CH}}\left(w^{*}\right)$ may be normalized by the reference stress of the in-plane torsion test at identical specific work $w^{*}$ (Fig. 8(b)), which gives the cross-hardening ratio

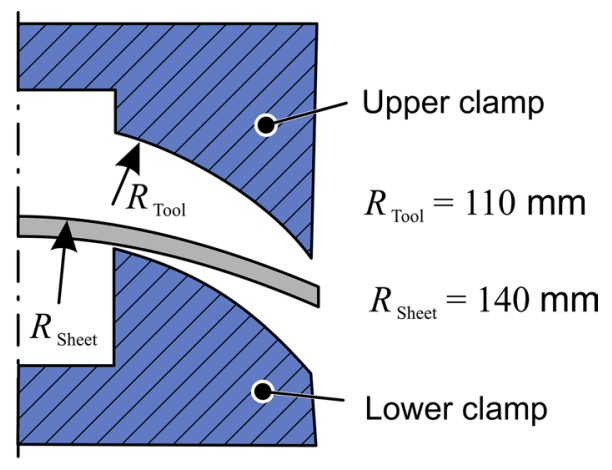

(a)

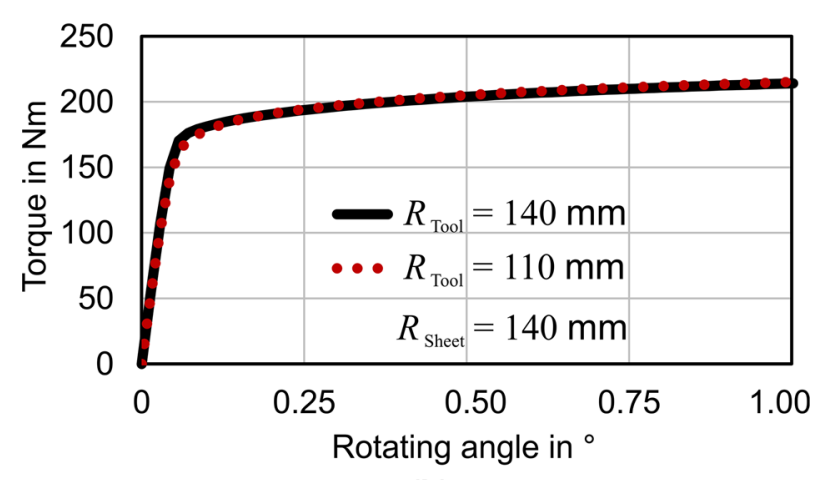

(b)

Fig. 9 (a) Setup for investigation of curvature deviations at clamping on the shear stress. (b) Torque at rotation for different clamping curvatures 
$C_{\mathrm{R}}\left(w^{*}\right)=\frac{\sigma_{\mathrm{CH}}\left(w^{*}\right)}{\sigma_{\text {in-plane torsion }}\left(w^{*}\right)} \cdot 100 \%$.

In case of no cross-hardening the $C_{\mathrm{R}}$ is 0 . The black curve in (Fig. 8(b)) represents the evolution of $C_{R}$ after the strainpath change and is calculated as the average of all tests for specific prestrain. The maximum value of that evolution is indicated by a red diamond. The corresponding specific work $w_{\mathrm{MaxCH}}$ is indicated in Fig. 8. The grey horizontal bar represents the variation of specific work for a specific prestrain, while the vertical bar represents the scatter of the maximum cross-hardening of the tests for specific prestrain.

With further deformation the stress overshoot $\sigma_{\mathrm{CH}}$ and hence the cross-hardening ratio $C_{R}$ decreases after a single strain-path change has occurred. A possible way to characterize the transient characteristic is to evaluate the change of $C_{R}$ after a certain amount of deformation. The amount

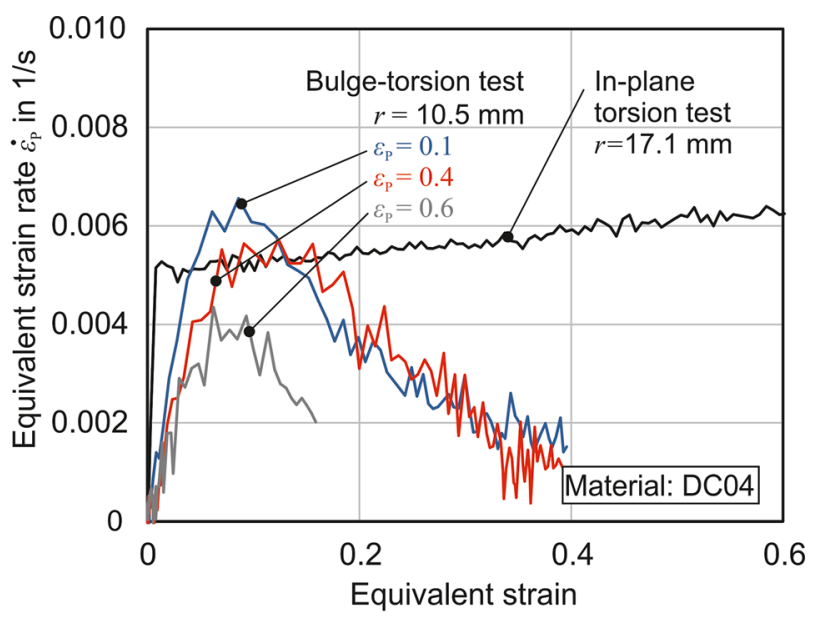

(a)

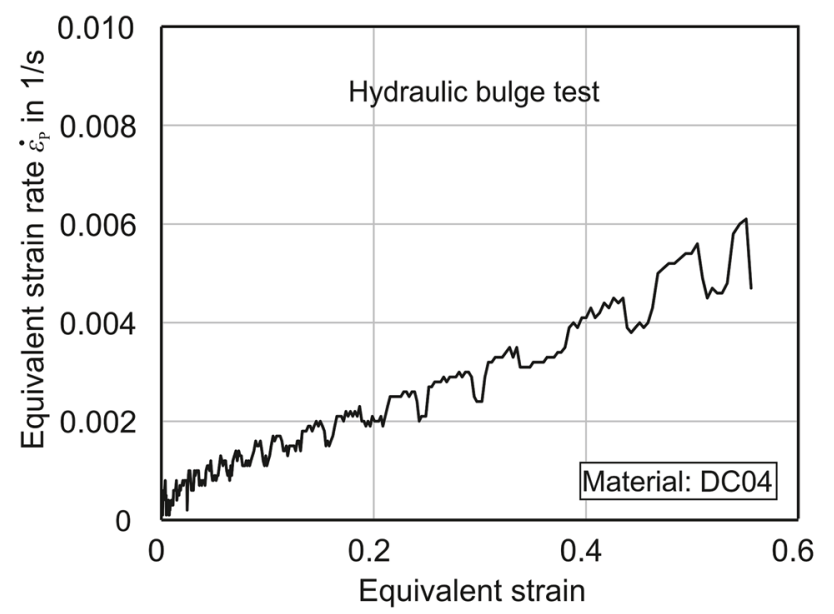

(b)

Fig. 10 Strain rate investigation for (a) in-plane torsions tests and (b) hydraulic bulge test should be large enough to cover significant deformation, but also small enough that it is also applicable to large prestrains, where only little formability is left. Thus, $20 \%$ of the specific work at maximum cross-hardening $w_{\mathrm{MaxCH}}$ is chosen (i.e., $1.2 w_{\mathrm{MaxCH}}$ ). The corresponding $C_{R}$ at $1.2 w_{\mathrm{MaxCH}}$ is marked with a red dot (Fig. 8(b)).

\section{Analysis of the New Setup}

As the bulge-torsion test setup aims to identify isolated changes of yield stress due to an orthogonal strain-path change, appropriate care must be taken to exclude changes in the yield stress by other reasons. Therefore, the influence on the yield stress by imperfect clamping conditions, strain rates and hydrostatic pressure in the tests is investigated. Finally, the overall advantages and limitations of the proposed setup are discussed.

\section{Clamping of Curved Sheets}

In practice, a curved sheet may not be tested with clamps of identical curvature. The deviation of the curvature between clamps and sheet might induce additional stress and strain, compared to the torsion of plane sheets. The superposed stress might affect the yield stress and thus, the necessary torque for in-plane shearing, compared to the torsion of plane sheets. This scenario has been investigated with an implicit 3D Finite-Element (FE) analysis. A $2.0 \mathrm{~mm}$ thick sheet with elastic-plastic behavior similar to DC04 has been modelled with $0.2 \mathrm{~mm}$ large elements. The sheet was chosen to have a curvature of $R_{\text {Sheet }}=140 \mathrm{~mm}$ on the upper surface (Fig. 9(a)). The tools have been modelled with the same curvature $\left(R_{\text {Tool }}=140 \mathrm{~mm}\right)$ and the next larger curvature of the manufactured clamps $\left(R_{\text {Tool }}=110 \mathrm{~mm}\right)$. In both cases the clamping force has been set to $100 \mathrm{kN}$ (as in the experiments). After the clamping force is applied, the sheet is rotated by the same amount for both configurations.

The evolution of torque shows a deviation of less than $0.16 \%$ (Fig. 9(b)). Thus, it is reasonable to assume, that a mismatch of the curvature radii between sheet and clamping tools has a negligible influence on the stress calculation. It is concluded from this analysis that the influence of the inner clamping on the torque is negligible for all clamps because the change of height to the next larger/smaller curvature $\Delta h$ is constant and less than $0.08 \mathrm{~mm}$ (cf. Fig. 7).

\section{Strain Rate and Viscous Effects}

Although all torsion tests have been performed at the constant rotation speed of $3.3 \% \mathrm{~min}$, the effective strain rate is varying. The strain rate depends on the angular velocity, but also on the radial position $r$ on the specimen and the hardening rate of the material. As the hardening rate is expected to 


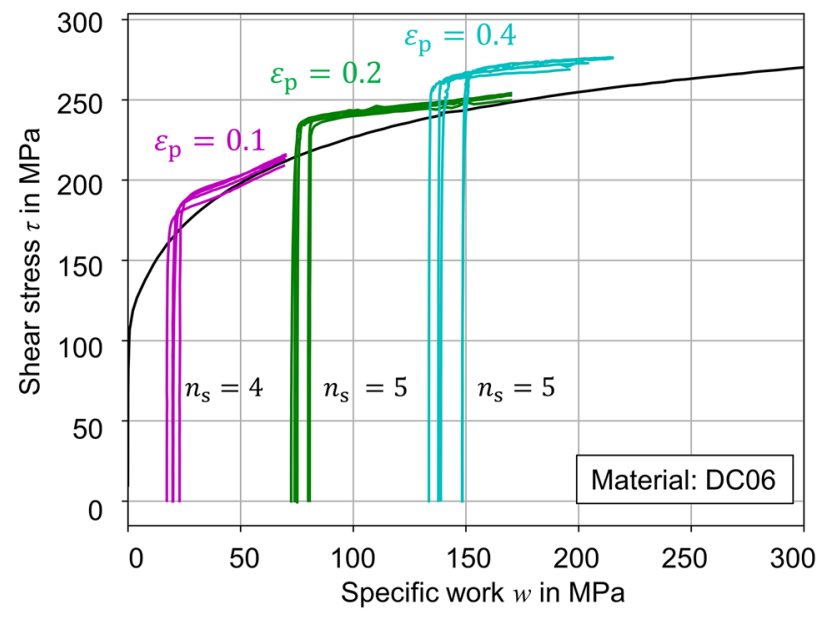

(a)

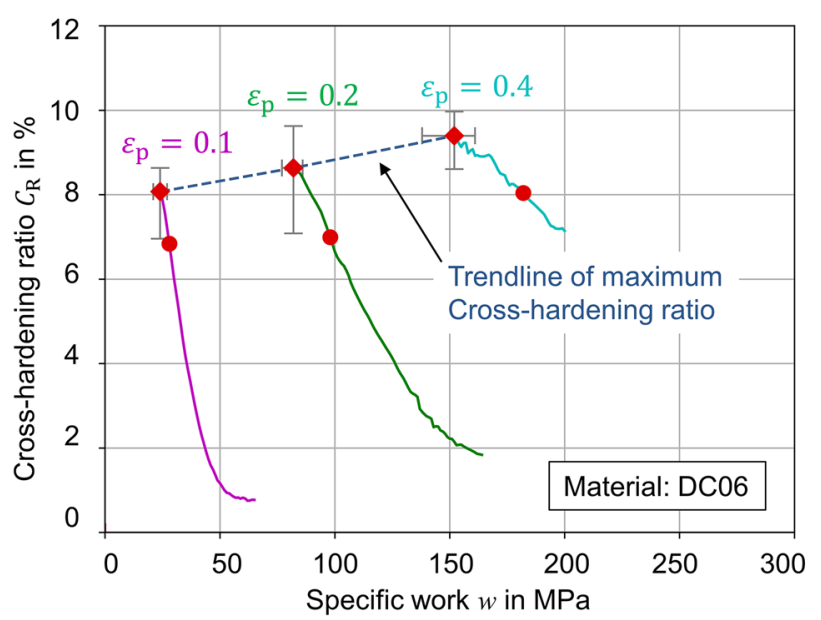

(b)

Fig. 11 Results of novel bulge-torsion Test for DC06. (a) Stress overshoot after orthogonal strain-path change. The parameter $n_{\mathrm{s}}$ specifies the number of samples. (b) Cross-hardening evolution

vary in the tests, the strain rate has been analyzed for DC04 for the monotonic torsion and the torsion after bulge for different prestrains from the bulge test (Fig. 10). All strain rates have been calculated as the ratio of von Mises strain increment and the time increment. For the monotonic torsion the strain rate starts at $0.0051 / \mathrm{s}$ and then mildly increases to $0.006 \mathrm{1} / \mathrm{s}$ at a plastic strain of 0.6 . For the bulge-torsion the strain rate starts between $0.0041 / \mathrm{s}$ and $0.0061 / \mathrm{s}$ and decreases with continued deformation. Thus, both torsion tests have approximately the same strain rate at the beginning of deformation. The strain rate of the bulge test has an almost linear increase up to 0.005 1/s (Fig. 10(b)). Due to the chosen test parameters the differences in the strain rates are approximately the same (until hardening stagnation). According to the work of Larour et al. [42] a factor of 2 in the strainrate would increase the yield stress less than $3 \%$ after 0.1 prestrain in mild steel and significantly less for

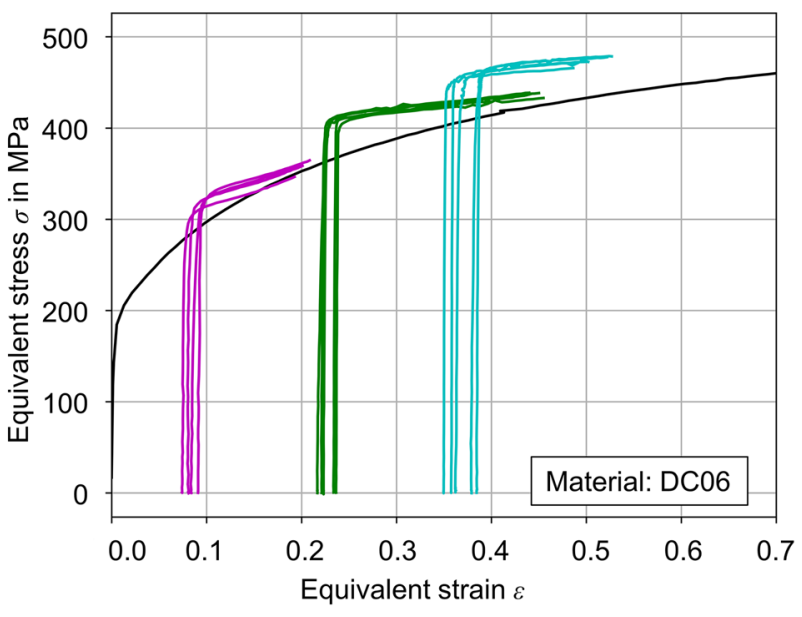

(a)

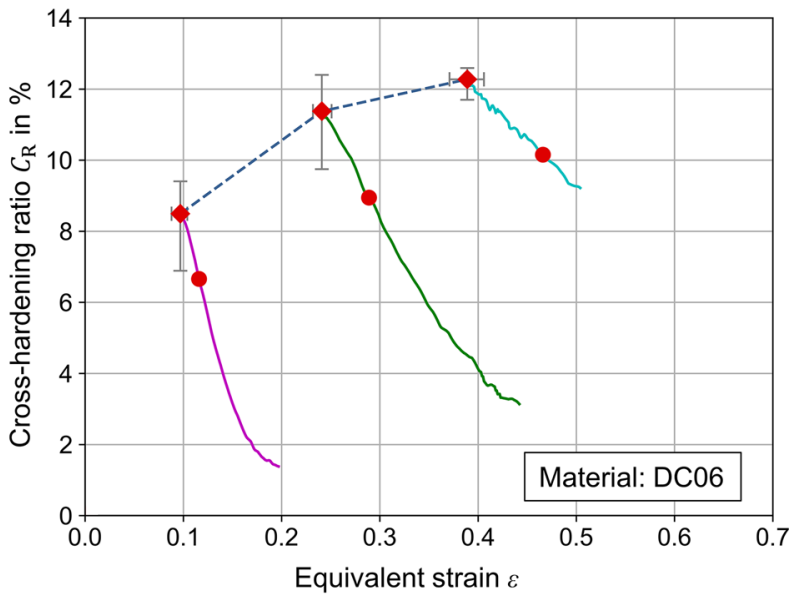

(b)

Fig. 12 Results of novel bulge-torsion Test evaluated with equivalent measures. (a) Stress overshoot of DC06 after orthogonal strain-path change. (b) Cross-hardening evolution of DC06

the high strength steels. The EN-ISO 6892-1 standard [31] allows strain rates up to $0.008 \mathrm{1} / \mathrm{s}$ for the determination of

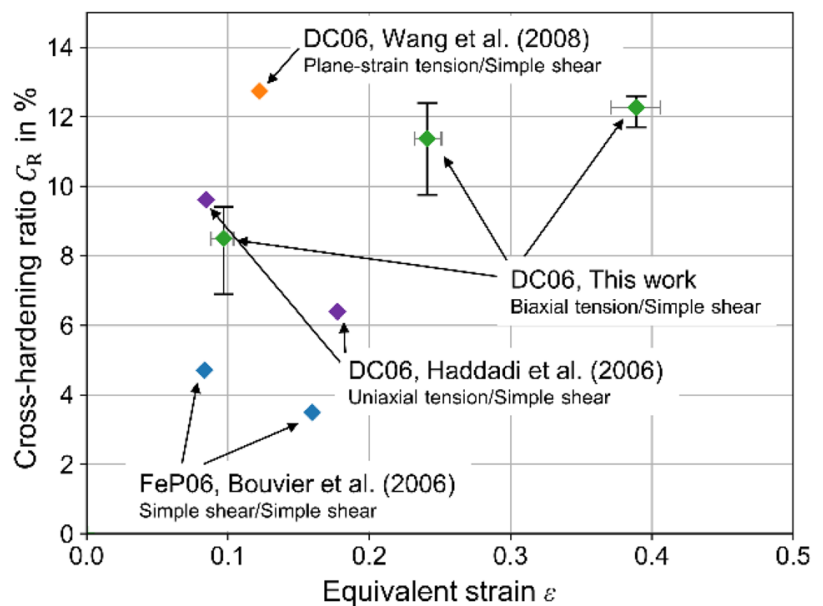

Fig. 13 Comparison of bulge-torsion test results for DC06 with experiments from literature. All tests evaluated with equivalent von Mises strain 
the tensile strength under quasi-static conditions. Therefore, it is also concluded that the tests are quasi-static.

The dense dislocation walls created during the prestrain test may partially recover afterwards. Experiments by Manik et al. [10] with commercially pure aluminum for intervals from several minutes to an entire year demonstrate that the stress overshoot decreases by approximately $20 \%$. However, this decrease seems to follow an exponential function. Thus, the decrease in overshoot is strongest during the first minutes after the prestrain test. The interval of the tests for the proposed setup has been between at least $2 \mathrm{~h}$ and 3 weeks.

\section{Hydrostatic Pressure Analysis}

Although, it is very common to assume that the hydrostatic pressure has no influence on the yield stress, a minor influence for steels has been reported [43]. However, the yield

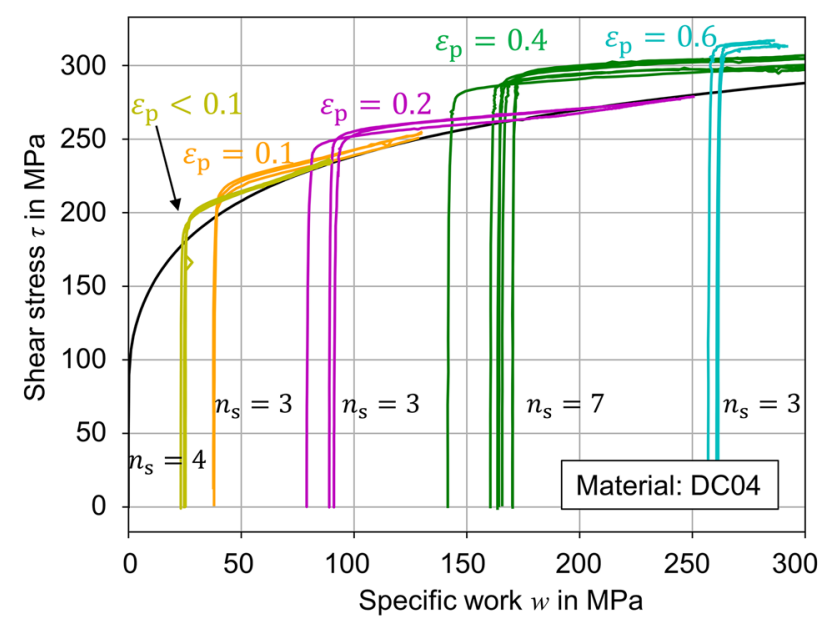

(a)

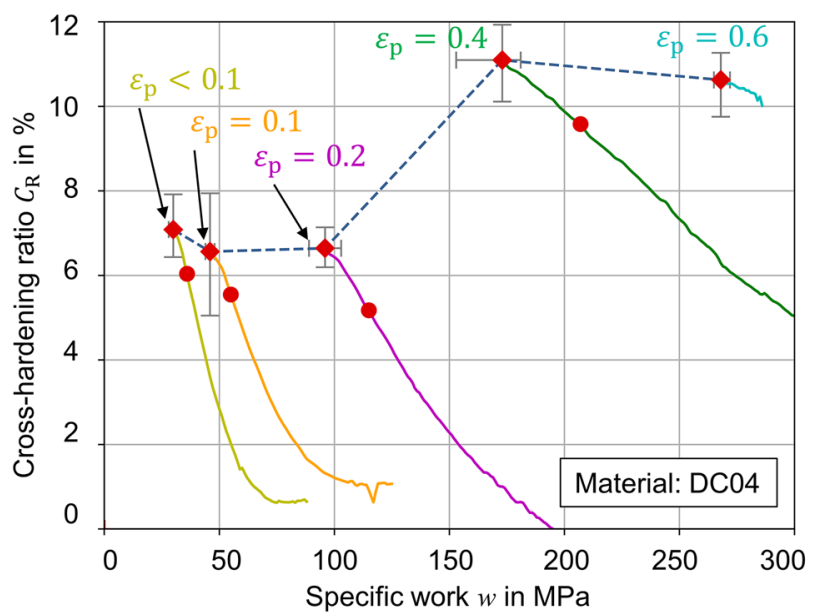

(b)

Fig. 14 Results of novel bulge-torsion Test for DC04. (a) Stress overshoot after orthogonal strain-path change. The parameter $n_{\mathrm{s}}$ specifies the number of samples. (b) Cross-hardening evolution stress in shear tests of plane and curved sheets is not affected by the pressure dependency because there is no hydrostatic pressure in shear. In the current case the stress overshoot is evaluated based on the comparison of tests involving a strain-path change in shear with a monotonic shear test. Yet, during the bulge test significant hydrostatic pressure $\sigma_{\mathrm{h}}=\frac{2}{3} \sigma_{\mathrm{B}}$ occurs. This might have an effect on the yield stress in bulge. Experimental work by Bridgman [44] has shown that the yield stress is only affected instantaneously by the hydrostatic pressure. After the forming operation the effect is no longer detectable.

\section{Advantages of the New Bulge-Torsion Test}

The reference test for the proposed setup is the conventional in-plane torsion test. The proposed bulge-torsion test combines biaxial tension applied by hydraulic bulge test and

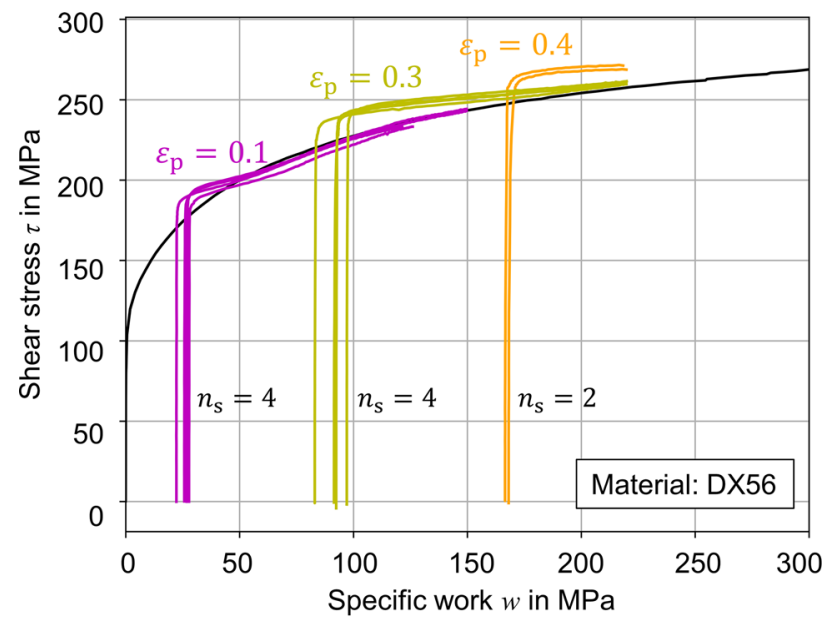

(a)

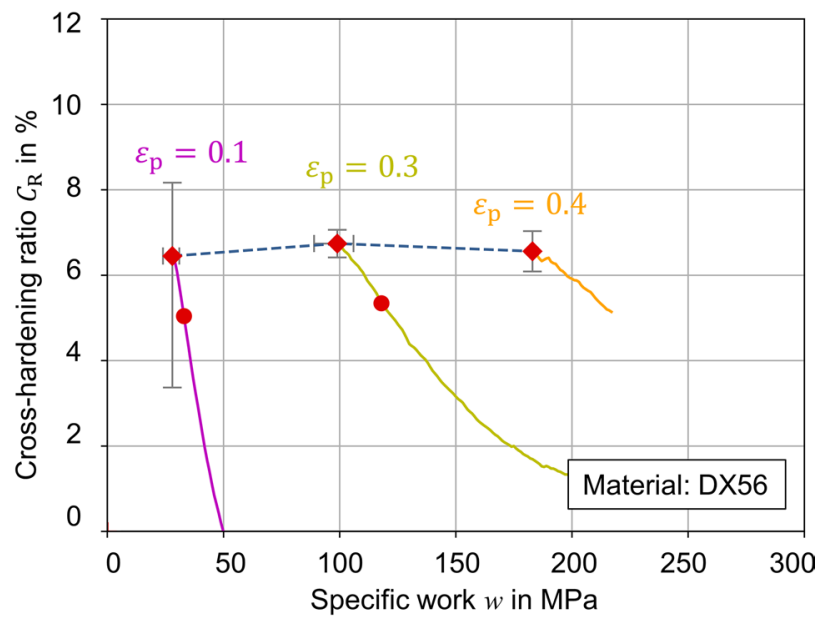

(b)

Fig. 15 Results of novel bulge-torsion Test for DX56. (a) Stress overshoot of after orthogonal strain-path change. The parameter $n_{\mathrm{s}}$ specifies the number of samples. (b) Cross-hardening evolution 


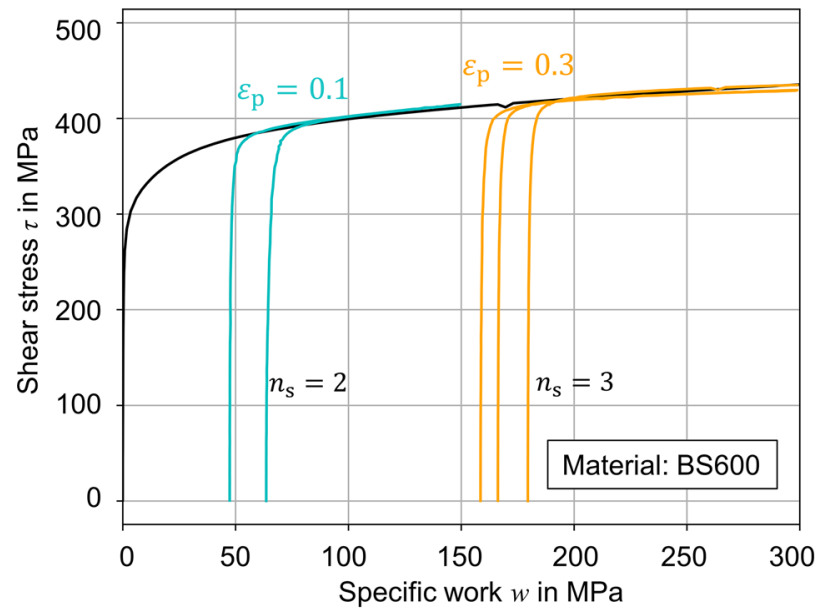

(a)

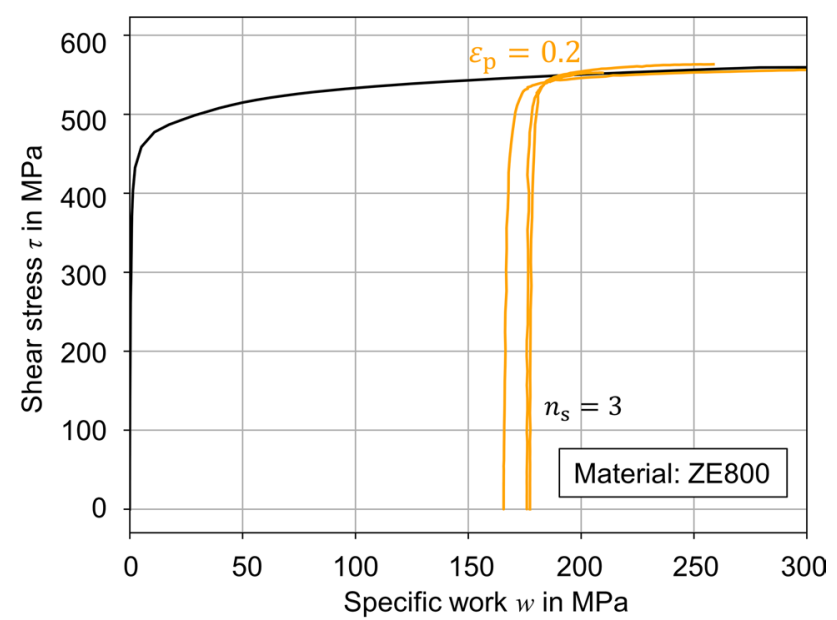

(b)

Fig. 16 Results of novel bulge-torsion Test for (a) BS600 and (b) ZE800. The parameter $n_{\mathrm{s}}$ specifies the number of samples

shear applied by in-plane torsion test at the curved sheet. Thus, large plastic strain can be applied in the first step. Equivalent prestrains up to 0.6 have been realized for the investigated grades with the current setups. In circumferential direction the strain is almost uniform. The concept of the bulge-torsion test does not require a mechanical trimming of the specimen between the loading steps. Therefore, the stress state after the application of the prestrain is not modified and no plastic strain or additional work-hardening is introduced due to machining operations. For comparison of shear and

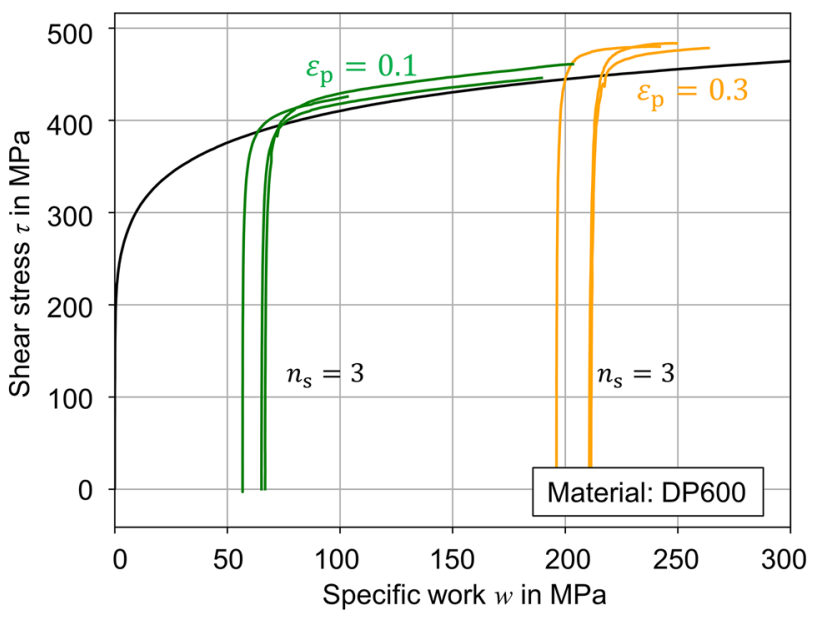

(a)

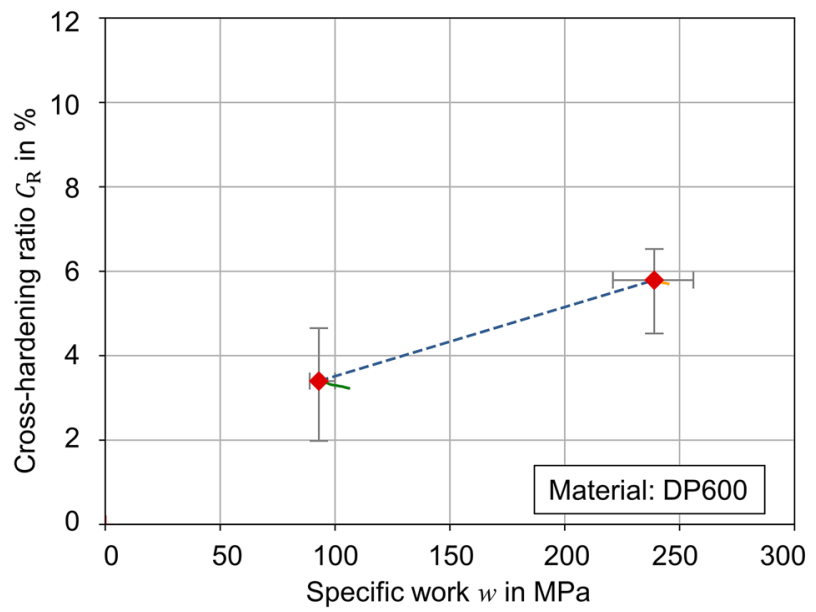

(b)

Fig. 17 Results of novel bulge-torsion Test for DP600. (a) Stress overshoot after orthogonal strain-path change. The parameter $n_{\mathrm{s}}$ specifies the number of samples. (b) Cross-hardening evolution

biaxial load the specific work is calculated, thus no constitutive assumption is required. The strain sequence from biaxial tension to simple shear ensures always an exactly orthogonal strain-path change. Due to the discrete steps the strain-path change is also abrupt. Finally, in the hydraulic bulge test and the in-plane torsion test stress and strain are averaged over the circumference. Therefore, integral measures are obtained. Consequently, the determined cross-hardening is isolated from the influence of anisotropic yield stresses.
Table 4 Summary of characterized cross-hardening ratio $C_{R}$ and key microstructure parameter of investigate steel grades (*DP600 evaluated at $\varepsilon_{\mathrm{p}}=0.3$ instead of $\varepsilon_{\mathrm{p}}=0.4$ )

\begin{tabular}{lllllll}
\hline Type & DC06 & DC04 & DX56 & BS600 & DP600 & ZE800 \\
\hline$C_{R}$ in $\%$ at $\varepsilon_{\mathrm{p}}=0.1$ & $8 \%$ & $7 \%$ & $6 \%$ & $0 \%$ & $3 \%$ & $0 \%$ \\
$C_{R}$ in $\%$ at $\varepsilon_{\mathrm{p}}=0.4$ & $9 \%$ & $11 \%$ & $6 \%$ & $0 \%$ & $6 \% *$ & $0 \%$ \\
Carbon content in $\%$ & 0.02 & 0.06 & 0.16 & 0.11 & 0.12 & 0.10 \\
Average grain size in $\mu \mathrm{m}$ & 9.5 & 27.5 & 15.0 & 27.0 & 8.5 & 35.0 \\
\hline
\end{tabular}




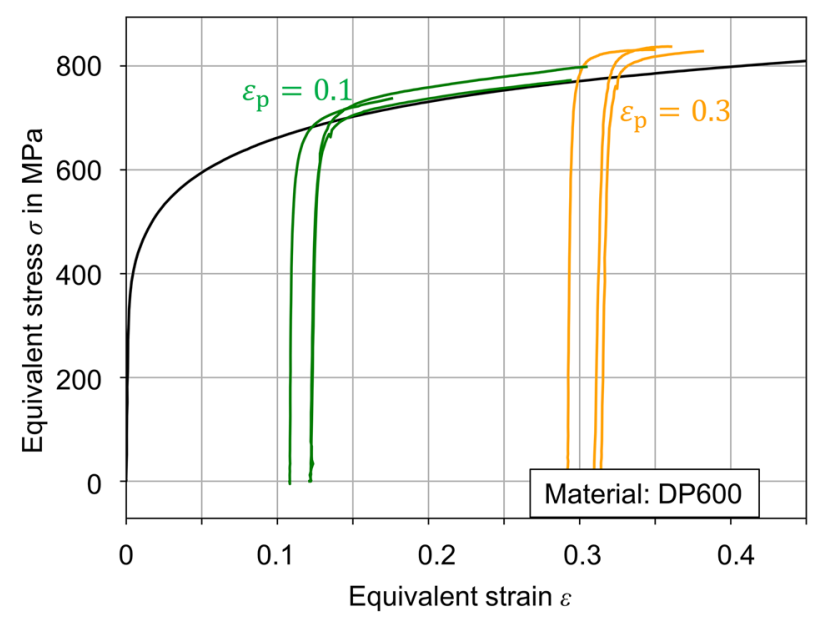

(a)

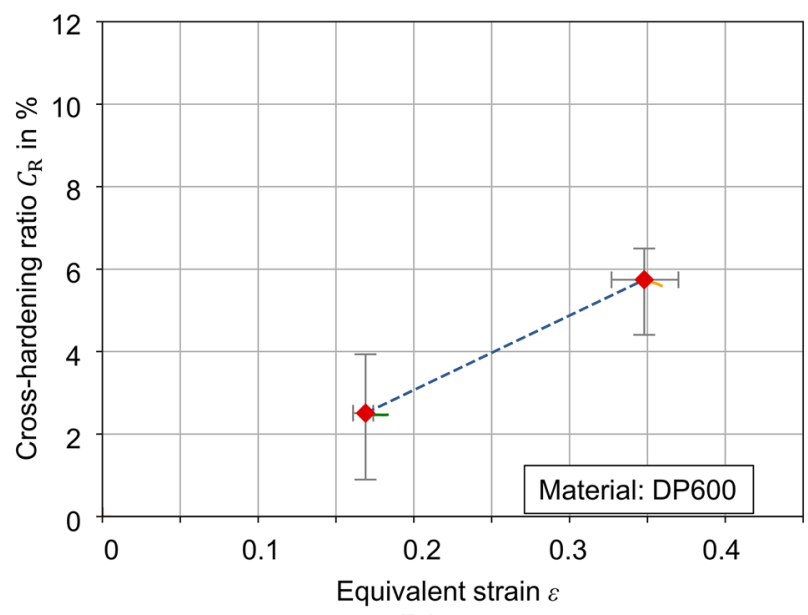

(b)

Fig. 18 Alternative evaluation of novel bulge-torsion Test by von Mises strain for DP600. (a) Stress overshoot after orthogonal strainpath change. (b) Cross-hardening evolution

\section{Disadvantages and Limitations}

Beside the advantages, the design of the setup has also some drawbacks.

Although mentioned previously as an advantage (from the forming technology point of view), one could argue that averaging material anisotropy in the torsion test is a disadvantage. Anisotropic materials may exhibit different amount of plastic work over the circumference. However, the reproducibility of the results is not affected due to the averaging over the circumference.

The determination of the biaxial stress in the bulge test following the ISO standard introduces some error. Min et al. [45] have shown that the error in the stress is as large as $3 \%$. This is a considerable uncertainty for the determination of the cross-hardening effect. Yet, this approach has been chosen, as it is a well-established procedure.
The high gradient of strain at the inner clamping of torsion test is a challenge for the DIC evaluation. Traphöner et al. [35] revealed that the strain will be overestimated. For DC04 the error is less than $0.5 \%$. However, this considers only the strain and not the stress. Therefore, the amount of cross-hardening is not affected.

It is not possible to determine the strain rate a priori in the in-plane torsion test for a specific test. Thus, an iterative approach was chosen to obtain a pre-defined value of the strain rate. Another aspect to consider is to obtain the desired curvature in the bulge test. A scatter up to $\Delta \varepsilon=0.05$ was observed for different test aiming at identical prestrains. A better accuracy cannot be obtained because the starting pressure in the hydraulic bulge test is determined by the oil level before the test, which is adjusted by the operator manually.

\section{Results and Discussion}

The results of the bulge-torsion test (i.e., the stress overshoot and cross-hardening) are presented for the DC06 steel grade first. On the basis of these results, possible uncertainties and scatter are discussed. This is followed by a comparison with results for cross-hardening obtained for this grade in previous works. Afterwards the results of bulge-torsion test are presented for the remaining grades.

\section{Stress Overshoot and Cross-Hardening for DC06}

The bulge-torsion test produces the typical instantaneous stress overshoot which was expected for DC06 (Fig. 11(a)). After further work the shear stress approaches the monotonic yield stress. For the large prestrain of 0.4 the specimen failed before the yield stress reached the monotonic curve again. The absolute value of the stress overshoot $\sigma_{\mathrm{CH}}$ increases with the amount of prestrain. Not only the absolute stress difference increases (Fig. 11(b)), but also the crosshardening ratio $C_{R}$ defined in (equation (9)). Small scatter in the determination of the shear stress has a large impact on the determined level of cross-hardening ratio. While the shear stress of bulge-torsion test curves has only a scatter of $2 \%(5 \mathrm{MPa} / 248 \mathrm{MPa})$ at $\varepsilon_{\mathrm{p}}=0.2$, the cross-hardening ratio $C_{R}$ varies relatively by $29 \%$ (between $7 \%$ and $9.5 \%$ ). The analysis is based on 5 repetitions at $\varepsilon_{\mathrm{p}}=0.2$ and $\varepsilon_{\mathrm{p}}=0.4$, and 4 repetitions at $\varepsilon_{\mathrm{p}}=0.1$. The cross-hardening ratio $C_{R}$ decreases monotonically with further deformation. The amount of cross-hardening after an additional $20 \%$ of specific work based on the previously performed work during the bulge test reveals that the rate is constant. The crosshardening ratio $C_{R}$ reduces to $85 \%$ and $86 \%$ of the initial, maximum cross-hardening for $\varepsilon_{\mathrm{p}}=0.1$ and $\varepsilon_{\mathrm{p}}=0.4$, respectively. Due to the increase of yield stress at larger strains, 
the amount of specific work also increases, thus the rate of decrease decreases in (Fig. 11(b)).

\section{Comparison with Literature}

The evaluation of stress overshoot and cross-hardening ratio by the performed specific work is not an intuitive measure. This is true especially, if the results should be used in forming operations with significant hardening. Therefore, it is desirable to evaluate the test in terms of an equivalent strain. Another reason is the ability to compare the results to other tests in the literature with different stress states.

The choice of von Mises equivalent strain shows a similar behavior for the stress overshoot (Fig. 12(a)) as the evaluation with the specific work. Yet, the analysis of cross-hardening ratio reveals differences (Fig. 12(b)). The cross-hardening ratios evaluated with the equivalent strain are between $5 \%$ larger (for $\varepsilon_{\mathrm{p}}=0.1$ ) and $31 \%$ larger (for $\varepsilon_{\mathrm{p}}=0.4$ ). Therefore, the evaluation with equivalent strain is feasible for a rough estimation of cross-hardening, but not for its exact determination.

In previous works focusing on the mechanical response of DC06 after an orthogonal strain-path change (Fig. 13) the amount of stress overshoot or cross-hardening was not quantified. Therefore, the published stress-strain curves have been re-evaluated. Due to the different stress states and the unknown amount of specific work for prestrain-step the evaluation is done with equivalent von Mises strain. Bouvier et al. [24] performed simple shear tests in the rolling direction $\left(0^{\circ}\right)$ and subsequent orthogonal tests at $45^{\circ}$ with respect to the rolling direction for a FeP06 steel grade, which is very similar to DC06. The prestrain in $0^{\circ}$ was applied up to 0.09 and 0.17 equivalent strain. The shear stress in $45^{\circ}$ direction was about $5 \%$ and $4 \%$ higher than for the monotonic shear stress. Haddadi et al. [6] have tested DC06 in uniaxial tension up to 0.1 and 0.2 true strain and subsequently cut shear specimen for shear tests. The $C_{R}$ has been identified to almost $10 \%$ and $7 \%$, respectively. Wang et al. [34] loaded DC06 in plane-strain tension up to an equivalent strain of 0.12. Subsequent shear stress was about $13 \%$ higher than for the monotonic case.

The results from literature reveal a $C_{R}$ between 5 and $13 \%$ at 0.1 prestrain for specific directions. For the same prestrain the bulge-torsion test evaluated with von Mises strain yields a $C_{R}$ of about $8 \%$. The cross-hardening determined with the new proposed bulge-torsion test is in the range of observed crosshardening in literature. But as shown previously in this section, the evaluation with equivalent strain causes significant deviation from the evaluation with specific work. For DC06 the $C_{R}$ determined based on the equivalent strain is up to $1 / 3$ different from the $C_{R}$ determined based on the specific work.

The proposed bulge-torsion test reveals an increasing maximum $C_{R}$ with increasing prestrain, which is in accordance to experimental observations and microstructural explanations of Rauch and Schmitt [2].

\section{Results for Other Steels}

For DC04 (Fig. 14) prestrains up to 0.6 have been realized. In case the remaining formability after the prestrain and strain-path change is sufficiently large, the yield curves of most experiments meet the monotonic curve (Fig. 14(a)). For the prestrain of 0.4 the subsequent yield curve converges to the monotonic curve. For the strain-path change after 0.6 prestrain the tests were stopped, when the torque had decreased significantly, as this indicates failure of the specimen. The cross-hardening increases from about $6 \%$ for small prestrains up to about $11 \%$ for large prestrains (Fig. 14(b)). After an additional $20 \%$ specific work the $C_{R}$ reduces to $85 \%$ and $86 \%$ of its initial, maximum $C_{R}$ for $\varepsilon_{\mathrm{p}}=0.1$ and $\varepsilon_{\mathrm{p}}=0.4$, respectively (cf. red dots in Fig. 14(b)). This is identical to the values for DC06.

For the DX56 steel grade (Fig. 15) the stress overshoot seems to look similar to the previous DC grades (Fig. 15(a)), but analysis of cross-hardening reveals that the maximum $C_{R}$ is about $7 \%$ for prestrain of 0.1 and 0.4 (Fig. 15(b)). Thus, it seems that the cross-hardening might be independent of the amount of prestrain. After additional $20 \%$ specific work the $C_{R}$ reduces to $78 \%$ of its initial, maximum value for $\varepsilon_{\mathrm{p}}=0.1$, which is significantly lower than for the DC grades. The determination of the reduction at $\varepsilon_{\mathrm{p}}=0.4$ was not possible, due to prior failure of the specimens in the bulge-torsion test.

For the high strength grades BS600 and ZE800 (Fig. 16) no stress overshoot is observed. Thus, no cross-hardening is determined. The absence of the stress overshoot for the BS600 may be explained with its special constitutive phase. The bainite phase is a composite of ferrite and cementite. The distribution of cementite might impede the formation of necessary characteristic patterns of dense dislocation walls during the monotonic deformation (cf. Appendix A).

For DP600 (Fig. 17(a)) the stress overshoot is atypical. The stress exceeds the monotonic reference stress and shows regular hardening behavior as in the monotonic case. Thus, the absolute stress overshoot $\sigma_{\mathrm{CH}}$ seems to be constant with further deformation. The absence of the typical softening after the stress overshoot is explained by a modified disintegration of the characteristic dense dislocation walls without micro shear-bands [46]. Analysis of the cross-hardening reveals that the $C_{R}$ increases with prestrain from 3 to $6 \%$ at $\varepsilon_{\mathrm{p}}=0.1$ and $\varepsilon_{\mathrm{p}}=0.3$, respectively (Fig. 17(b)). Alternative evaluation by equivalent von Mises strain confirms the presented results qualitatively (Fig. 18). Yet, the amount of $C_{R}$ is $26 \%$ and less than $1 \%$ lower at $\varepsilon_{\mathrm{p}}=0.1$ and $\varepsilon_{\mathrm{p}}=0.3$. This corresponds to the alternative evaluation for DC06, which also confirmed the qualitative results, but quantitatively had significant differences.

The work of Haddadi et al. [6] reports no deviation from monotonic strain-path for DP600 at prestrains of 0.1 and 0.2 true plastic strain. The authors had used a sequence of 
uniaxial tension and simple shear. The applied method for shifting the prestrained test data by the uniaxial prestrain is not explicitly stated.

In summary, the hypothesis concerning characterization of the material cannot be confirmed. The mild steels (DC06, DC04 and DX56) with significant cross-hardening have carbon contents between $0.02 \%$ and $0.16 \%$ and grainsizes between $10 \mu \mathrm{m}$ and $28 \mu \mathrm{m}$. Yet the single-phase highstrength steels do not show any cross-hardening, although ZE800 and BS600 have carbon content below $0.11 \%$ and large grain-sizes of $35 \mu \mathrm{m}$ and $27 \mu \mathrm{m}$, respectively. Thus, there have to be additional parameters that influence the mobility of dislocations to form the typical pattern, which are supposed to cause the cross-hardening effect.

\section{Conclusions}

Different mild steels (DC06, DC04 and DX56) and high strength steels (DP600, BS600, ZE800) have been tested for cross-hardening in a novel setup. It is demonstrated that the bulge-torsion test is suited to determine cross-hardening. The proposed setup enables the characterization of crosshardening at prestrains up to 0.6 for the first time. The analysis reveals that the normalized cross-hardening ratio $C_{R}$ of DC grades increases mildly with increasing prestrain, while it seems to be constant at $6 \%$ for the DX56 (Table 4). Thus, it can be concluded that the absolute stress of cross-hardening always increases, even at large strains. The reduced maximum $C_{R}$ for the DX56 grade may be caused by the higher amount of carbon in the microstructure which impedes the formation of more pronounced dense dislocation walls. The decrease of cross-hardening with further deformation has been quantified by the reduction of $C_{R}$ after additional $20 \%$ work. The DC grades had a constant reduction of $C_{R}$ to about $85 \%$, while the DX grade reduced to $78 \%$.

Surprisingly, the dual-phase steel DP600 revealed also some mild cross-hardening for prestrains of 0.1 and 0.3 . BS600 and ZE800 have been investigated the first time for the cross-hardening effect and are not sensitive for crosshardening. A cross-hardening effect might have been possible, due to their virtually single-phase microstructure and moderate amount of carbon and large grain-size. It is supposed that other parameters impede the mobility of the dislocations to form the necessary patterns.

It has been demonstrated that the method to compare different load types has a significant influence on the determined cross-hardening.

Acknowledgements The authors thank Dr. Gregory Gerstein (Institut für Werkstoffkunde, Leibniz Universität Hannover) for providing measurements of average grain size and carbon content of investigated steels.
Funding Open Access funding enabled and organized by Projekt DEAL. The work has been funded by the German Research Foundation (DFG) within the scope of the Transregional Collaborative Research Centre for sheet-bulk metal forming (TCRC 73, Subproject C4) under grant number 68237143 .

\section{Declarations}

Conflict of Interest The authors declare that they have no conflict of interest.

Open Access This article is licensed under a Creative Commons Attribution 4.0 International License, which permits use, sharing, adaptation, distribution and reproduction in any medium or format, as long as you give appropriate credit to the original author(s) and the source, provide a link to the Creative Commons licence, and indicate if changes were made. The images or other third party material in this article are included in the article's Creative Commons licence, unless indicated otherwise in a credit line to the material. If material is not included in the article's Creative Commons licence and your intended use is not permitted by statutory regulation or exceeds the permitted use, you will

\section{Appendix A}

See Fig. 19.

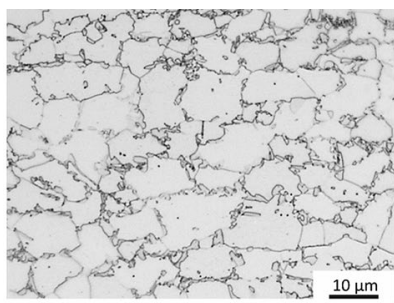

DC06

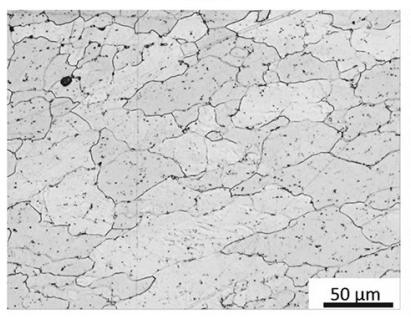

DC04

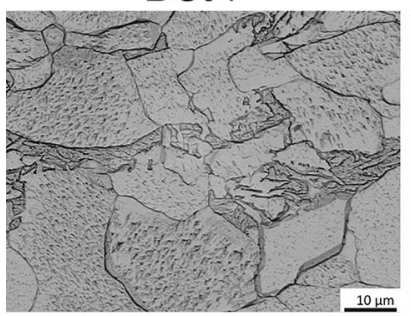

DX56

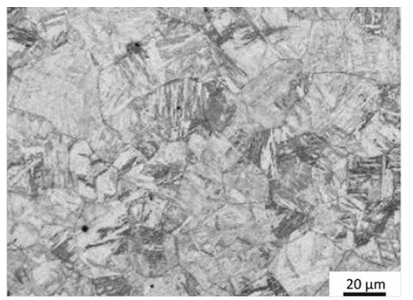

BS600

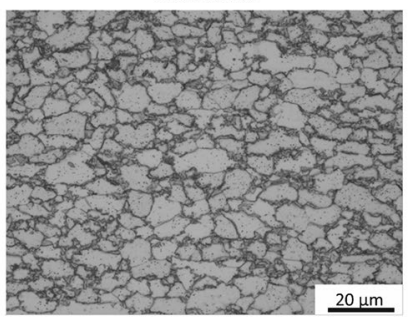

DP600

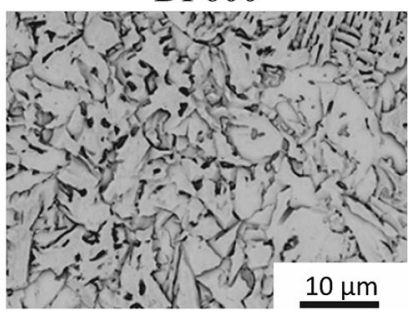

ZE800
Fig. 19 Light microscopy images of the investigated steels. The steels have been etched 


\section{Appendix B}

Measured data in hydraulic bulge test (prestrain test).

\begin{tabular}{|c|c|c|c|}
\hline \multicolumn{4}{|l|}{ DC06 } \\
\hline Sample number & $\begin{array}{l}\text { Specific } \\
\text { work } w \text { in } \\
\text { MPa }\end{array}$ & $\begin{array}{l}\text { Thick- } \\
\text { ness } \\
\text { strain } \varepsilon_{\mathrm{p}}\end{array}$ & $\begin{array}{l}\text { Curvature } \\
\text { radius } \\
R_{\text {Bulge, min }}\end{array}$ \\
\hline 1 & 22.92 & 0.091 & 140.6 \\
\hline 2 & 20.08 & 0.083 & 146.8 \\
\hline 3 & 19.89 & 0.081 & 148.8 \\
\hline 4 & 17.29 & 0.074 & 155.7 \\
\hline 5 & 75.18 & 0.223 & 92.3 \\
\hline 6 & 72.47 & 0.217 & 93.4 \\
\hline 7 & 74.03 & 0.221 & 92.4 \\
\hline 8 & 79.99 & 0.234 & 90.3 \\
\hline 9 & 80.67 & 0.236 & 90.2 \\
\hline 10 & 148.35 & 0.379 & 75.0 \\
\hline 11 & 148.47 & 0.385 & 74.8 \\
\hline 12 & 133.60 & 0.349 & 77.3 \\
\hline 13 & 137.76 & 0.357 & 77.2 \\
\hline 14 & 138.88 & 0.362 & 76.6 \\
\hline \multicolumn{4}{|l|}{ DC04 } \\
\hline Sample number & $\begin{array}{l}\text { Specific } \\
\text { work } w \text { in } \\
\mathrm{MPa}\end{array}$ & $\begin{array}{l}\text { Thick- } \\
\text { ness } \\
\text { strain } \varepsilon_{\mathrm{p}}\end{array}$ & $\begin{array}{l}\text { Curvature } \\
\text { radius } \\
R_{\text {Bulge, min }}\end{array}$ \\
\hline 1 & 23.23 & 0.087 & 146.7 \\
\hline 2 & 25.00 & 0.092 & 142.0 \\
\hline 3 & 25.28 & 0.093 & 140.0 \\
\hline 4 & 24.71 & 0.091 & 141.6 \\
\hline 5 & 37.95 & 0.130 & 117.9 \\
\hline 6 & 37.66 & 0.128 & 118.7 \\
\hline 7 & 37.96 & 0.128 & 118.6 \\
\hline 8 & 91.11 & 0.250 & 89.7 \\
\hline 9 & 79.04 & 0.222 & 93.6 \\
\hline 10 & 89.04 & 0.246 & 89.7 \\
\hline 11 & 170.34 & 0.407 & 73.1 \\
\hline 12 & 170.23 & 0.408 & 73.2 \\
\hline 13 & 165.72 & 0.400 & 73.7 \\
\hline 14 & 163.65 & 0.396 & 74.1 \\
\hline 15 & 160.46 & 0.389 & 74.2 \\
\hline 16 & 164.27 & 0.399 & 73.6 \\
\hline 17 & 141.59 & 0.352 & 77.2 \\
\hline 18 & 260.73 & 0.571 & 65.4 \\
\hline 19 & 256.99 & 0.570 & 65.0 \\
\hline 20 & 261.45 & 0.573 & 65.2 \\
\hline
\end{tabular}

\begin{tabular}{|c|c|c|c|c|}
\hline \multicolumn{5}{|l|}{ DX56 } \\
\hline $\begin{array}{l}\text { Sample } \\
\text { number }\end{array}$ & $\begin{array}{l}\text { Specific work } w \\
\text { in } \mathrm{MPa}\end{array}$ & \multicolumn{2}{|c|}{$\begin{array}{l}\text { Thickness strain } \\
\varepsilon_{\mathrm{p}}\end{array}$} & $\begin{array}{l}\text { Curvature } \\
\text { radius } \\
R_{\text {Bulge, min }}\end{array}$ \\
\hline 1 & 22.28 & \multicolumn{2}{|c|}{0.085} & 147.4 \\
\hline 2 & 25.74 & \multicolumn{2}{|c|}{0.095} & 137.5 \\
\hline 3 & 26.83 & \multicolumn{2}{|c|}{0.098} & 135.3 \\
\hline 4 & 27.81 & \multicolumn{2}{|c|}{0.101} & 132.6 \\
\hline 5 & 83.02 & \multicolumn{2}{|c|}{0.233} & 91.6 \\
\hline 6 & 91.46 & \multicolumn{2}{|c|}{0.252} & 88.4 \\
\hline 7 & 92.42 & \multicolumn{2}{|c|}{0.253} & 88.5 \\
\hline 8 & 97.08 & \multicolumn{2}{|c|}{0.263} & 87.3 \\
\hline 9 & 166.55 & \multicolumn{2}{|c|}{0.404} & 73.8 \\
\hline 10 & 168.13 & \multicolumn{2}{|c|}{0.408} & 73.3 \\
\hline \multicolumn{5}{|l|}{ BS600 } \\
\hline $\begin{array}{l}\text { Sample } \\
\text { number }\end{array}$ & $\begin{array}{l}\text { Specific work } w \\
\text { in } \mathrm{MPa}\end{array}$ & \multicolumn{2}{|c|}{$\begin{array}{l}\text { Thickness strain } \\
\varepsilon_{\mathrm{p}}\end{array}$} & $\begin{array}{l}\text { Curvature } \\
\text { radius } \\
R_{\text {Bulge, min }}\end{array}$ \\
\hline 1 & 63.60 & \multicolumn{2}{|c|}{0.113} & 140.9 \\
\hline 2 & 47.43 & \multicolumn{2}{|c|}{0.085} & 158.9 \\
\hline 3 & 158.56 & 0.2 & & 96.3 \\
\hline 4 & 179.54 & 0.2 & & 95.6 \\
\hline 5 & 166.26 & 0.2 & & 95.0 \\
\hline DP600 & & & & \\
\hline $\begin{array}{l}\text { Sample } \\
\text { number }\end{array}$ & $\begin{array}{l}\text { Specific work } w \\
\text { in MPa }\end{array}$ & $\begin{array}{l}\text { Thi } \\
\varepsilon_{\mathrm{p}}\end{array}$ & ness strain & $\begin{array}{l}\text { Curvature } \\
\text { radius } \\
R_{\text {Bulge, min }} \\
\end{array}$ \\
\hline 1 & 65.16 & 0.1 & & 127.4 \\
\hline 2 & 66.78 & 0.1 & & 131.1 \\
\hline 3 & 56.79 & 0.1 & & 137.3 \\
\hline 4 & 196.14 & 0.2 & & 89.4 \\
\hline 5 & 210.70 & 0.3 & & 85.6 \\
\hline 6 & 211.51 & 0.3 & & 86.4 \\
\hline ZE800 & & & & \\
\hline Sample $\mathrm{r}$ & $\begin{array}{l}\text { Speci } \\
\text { work } \\
\text { MPa }\end{array}$ & & $\begin{array}{l}\text { Thickness } \\
\text { strain } \varepsilon_{\mathrm{p}}\end{array}$ & $\begin{array}{l}\text { Curvature } \\
\text { radius } \\
R_{\text {Bulge, min }}\end{array}$ \\
\hline 1 & 175.9 & & 0.196 & 105.8 \\
\hline 2 & 165.6 & & 0.184 & 109.9 \\
\hline 3 & 177.3 & & 0.195 & 109.1 \\
\hline
\end{tabular}

Appendix C

Analysis of torsion radius in bulge-torsion test on test results Fig. 20. 


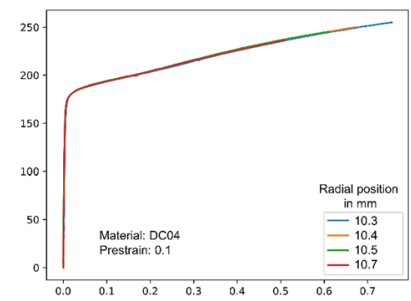

(a)

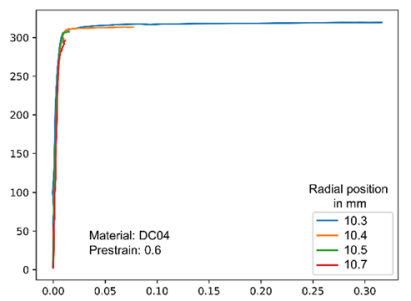

(b)
Fig. 20 Shear stress - shear strain curves of DC04 steel grad evaluated at different radial positions. (a) At low prestrain and thus larger hardening. (b) At large prestrain and thus lower hardening and remaining formability

\section{Appendix D}

Examples of strain fields from DIC measurements in the bulge-torsion test Fig. 21.

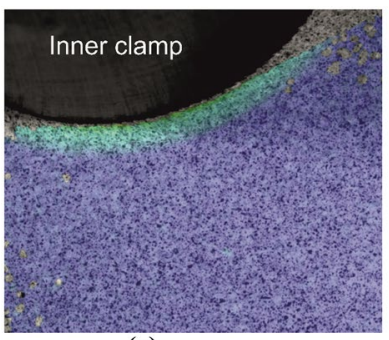

(a)

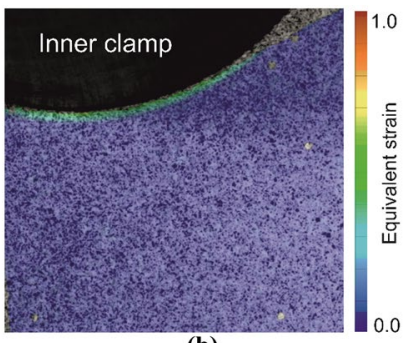

(b)
Fig. 21 Strain field of DC04 steel grade in the bulge-torsion test. (a) Prestrain of 0.13 ; (b) Prestrain of 0.4

need to obtain permission directly from the copyright holder. To view a copy of this licence, visit http://creativecommons.org/licenses/by/4.0/.

\section{References}

1. Laukonis JV, Ghosh AK (1978) Effects of strain path changes on the formability of sheet metals. Metall and Mat Trans A 9:1849-1856

2. Rauch EF, Schmitt J-H (1989) Dislocation substructures in mild steel deformed in simple shear. Material Science and Engineering A 113:441-448

3. Li B, Godfrey A, Meng Q et al (2004) Microstructural evolution of IF-steel during cold rolling. Acta Mater 52:1069-1081

4. Nesterova EV, Bacroix B, Teodosiu C (2001) Microstructure and texture evolution under strain-path changes in low-carbon interstitial-free steel. Metall and Mater Trans A 32:2527-2538

5. Holmedal B, van Houtte P, An Y (2008) A crystal plasticity model for strain-path changes in metals. Int J Plast 24:1360-1379

6. Haddadi H, Bouvier S, Banu M et al (2006) Towards an accurate description of the anisotropic behaviour of sheet metals under large plastic deformations: Modelling, numerical analysis and identification. Int J Plast 22:2226-2271
7. Lopes AB, Barlat F, Gracio JJ et al (2003) Effect of texture and microstructure on strain hardening anisotropy for aluminum deformed in uniaxial tension and simple shear. Int J Plast 19:1-22

8. Teodosiu C, Hu Z (1995) Evolution of the intragranular microstructure at moderate and large strains: modelling and computational significance. Simulation of materials processing: theory, methods and applications 173-182

9. Choi Y, Han C-S, Lee JK et al (2006) Modeling multi-axial deformation of planar anisotropic elasto-plastic materials, part I: Theory. Int J Plast 22:1745-1764

10. Mánik T, Holmedal B, Hopperstad OS (2015) Strain-path change induced transients in flow stress, work hardening and r-values in aluminum. Int J Plast 69:1-20

11. Levkovitch V, Svendsen B (2007) Accurate hardening modeling as basis for the realistic simulation of sheet forming processes with complex strain-path changes. In: AIP Conference Proceedings. AIP, pp 358-363

12. Feigenbaum HP, Dafalias YF (2007) Directional distortional hardening in metal plasticity within thermodynamics. Int J Solids Struct 44:7526-7542

13. Barlat F, Ha J, Grácio JJ et al (2013) Extension of homogeneous anisotropic hardening model to cross-loading with latent effects. Int J Plast 46:130-142

14. Barlat F, Vincze G, Grácio JJ et al (2014) Enhancements of homogenous anisotropic hardening model and application to mild and dual-phase steels. Int J Plast 58:201-218

15. Qin J, Holmedal B, Hopperstad OS (2018) A combined isotropic, kinematic and distortional hardening model for aluminum and steels under complex strain-path changes. Int J Plast 101:156-169

16. van Riel M, van den Boogaard T (2007) Stress-strain responses for continuous orthogonal strain path changes with increasing sharpness. Scripta Mater 57:381-384

17. Schmitt JH, Aernoudt E, Baudelet B (1985) Yield loci for polycrystalline metals without texture. Mater Sci Eng 75:13-20

18. Ghosh AK, Backofen WA (1973) Strain-hardening and instability in biaxially stretched sheets. Metallurgical Transactions 4:1113-1123

19. Wagoner RH, Laukonis JV (1983) Plastic behavior of aluminumkilled steel following plane-strain deformation. Metall Trans A 14:1487-1495

20. Lloyd DJ, Sang H (1979) The influence of strain path on subsequent mechanical properties-Orthogonal tensile paths. Metall Trans A 10:1767-1772

21. Raphanel JL, Schmitt JH, Baudelet B (1986) Effect of a prestrain on the subsequent yielding of low carbon steel sheets: experiments and simulations. Int J Plast 2:371-378

22. Ha J, Lee M-G, Barlat F (2013) Strain hardening response and modeling of EDDQ and DP780 steel sheet under non-linear strain path. Mech Mater 64:11-26

23. Zaman SB, Barlat F, Kim JH (2018) Deformation-induced anisotropy of uniaxially prestrained steel sheets. Int J Solids Struct 134:20-29

24. Bouvier S, Gardey B, Haddadi H et al (2006) Characterization of the strain-induced plastic anisotropy of rolled sheets by using sequences of simple shear and uniaxial tensile tests. J Mater Process Technol 174:115-126

25. Boers SHA, Schreurs PJG, Geers MGD et al (2010) Experimental characterization and model identification of directional hardening effects in metals for complex strain path changes. Int J Solids Struct 47:1361-1374

26. Sieczkarek P, Wernicke S, Gies $S$ et al (2016) Incipient and repeatable plastic flow in incremental sheet-bulk forming of gears. Int $\mathrm{J}$ Adv Manuf Technol 86:3091-3100

27. von Mises R (1913) Mechanik der festen Körper im plastischdeformablen Zustand. Nachrichten von der Gesellschaft der 
Wissenschaften zu Göttingen, Mathematisch-Physikalische Klasse 1:582-592

28. Hill R (1983) The mathematical theory of plasticity. Oxford science publications, vol 11. Clarendon Press, Oxford

29. Schmitt JH, Shen EL, Raphanel JL (1994) A parameter for measuring the magnitude of a change of strain path: Validation and comparison with experiments on low carbon steel. Int J Plast 10:535-551

30. Verband der Automobilindustrie (2016) Sheet steel for cold forming: Flacherzeugnisse aus Stahl zur Kaltumformung 239-100

31. EN-ISO 6892-1 (2017) EN-ISO 6892-1 Metallic materials - Tensile testing: Part 1: Method of test at room temperature 77.040.10(6892-1)

32. EN-ISO 10275 (2014) Metallic materials - Sheet and strip - Determination of tensile strain hardening exponent 77.040.10(10275)

33. EN-ISO 10113 (2017) Metallic materials - Sheet and strip Determination of plastic strain ratio 77.040.10(10113)

34. Wang J, Levkovitch V, Reusch F et al (2008) On the modeling of hardening in metals during non-proportional loading. Int J Plast 24:1039-1070

35. Traphöner H, Clausmeyer T, Tekkaya AE (2021) Methods for measuring large shear strains in in-plane torsion tests. J Mater Process Technol 287: 116516

36. EN-ISO-16808 (2014) Metallic materials - Sheet and strip Determination of biaxial stress-strain curve by means of bulge test with optical measuring systems 77.040.10(16808). Accessed 15 Apr 2019

37. Tekkaya AE, Pöhlandt K, Lange K (1982) Determining StressStrain Curves of Sheet Metal in the Plane Torsion Test. CIRP Ann 31:171-174
38. Yin Q, Tekkaya AE, Traphoner H (2015) Determining cyclic flow curves using the in-plane torsion test. CIRP Ann-Manuf Technol 64:261-264

39. Traphöner H, Clausmeyer T, Tekkaya AE (2018) Material characterization for plane and curved sheets using the in-plane torsion test - An overview. J Mater Process Technol 257:278-287

40. Traphöner H (2020) Erweiterung der Anwendungsgrenzen des ebenen Torsionsversuchs, 1. Auflage. Dortmunder Umformtechnik, vol 110. Shaker, Düren

41. Gutknecht F, Gerstein G, Traphöner H et al (2018) Experimental setup to characterize flow-induced anisotropy of sheet metals. IOP Conf Ser.: Mater Sci Eng 418: 12085

42. Larour P, Bäumer A, Dahmen K et al (2013) Influence of Strain Rate, Temperature, Plastic Strain, and Microstructure on the Strain Rate Sensitivity of Automotive Sheet Steels. steel research international 84: 426-442

43. Spitzig WA, Sober RJ, Richmond O (1976) The effect of hydrostatic pressure on the deformation behavior of maraging and HY-80 steels and its implications for plasticity theory. Metall and Mat Trans A 7:1703-1710

44. Bridgman PW (2013) Studies in Large Plastic Flow and Fracture: With Special Emphasis on the Effects of Hydrostatic Pressure. Harvard University Press, Cambridge (MA)

45. Min J, Stoughton TB, Carsley JE et al (2017) Accurate characterization of biaxial stress-strain response of sheet metal from bulge testing. Int J Plast 94:192-213

46. Gardey B, Bouvier S, Richard V et al (2005) Texture and dislocation structures observation in a dual-phase steel under strain-path changes at large deformation. Mater Sci Eng, A 400-401:136-141

Publisher's Note Springer Nature remains neutral with regard to jurisdictional claims in published maps and institutional affiliations. 